|||||||| BANK OF CANADA

BANQUE DU CANADA

Staff Working Paper/Document de travail du personnel — 2021-54

Last updated: November 4, 2021

\title{
Evaluating the Effects of Forward Guidance and Large-Scale Asset Purchases
}

by Xu Zhang

Financial Markets Department

Bank of Canada, Ottawa, Ontario K1A 0G9

XZhang@bankofcanada.ca

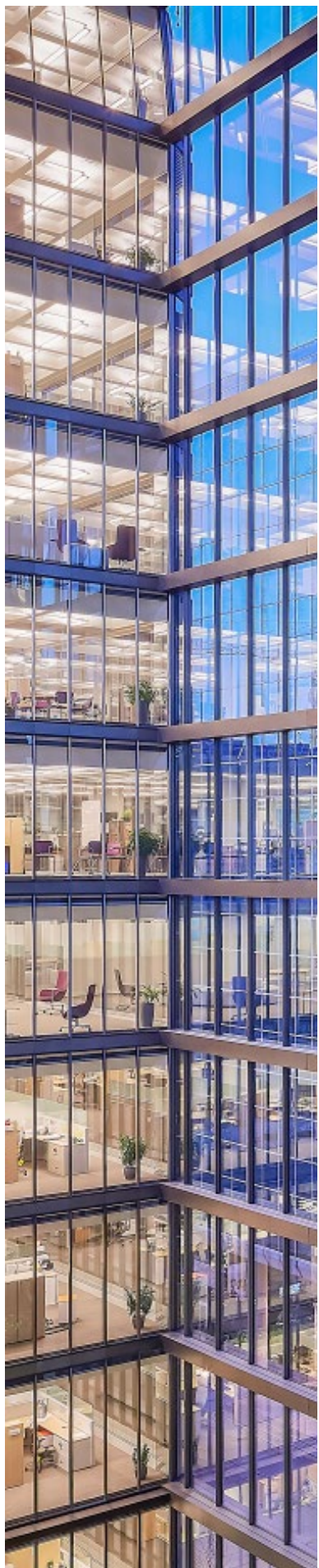

Bank of Canada staff working papers provide a forum for staff to publish work-in-progress research independently from the Bank's Governing Council. This research may support or challenge prevailing policy orthodoxy. Therefore, the views expressed in this paper are solely those of the authors and may differ from official Bank of Canada views. No responsibility for them should be attributed to the Bank. 


\section{Acknowledgements}

I thank James Hamilton, Johannes Wieland, David Lagakos, Tommaso Porzio, Giacomo

Rondina, Ross Starr, Alisdair McKay, Adam Guren, Nelson Lind, Leland Farmer, Fan (Dora) Xia,

Pavel Kapinos, Bruno Feunou, and seminar and conference participants at the University of California San Diego, 2018 ASSA annual meeting, 5th IAAE annual meeting, SED annual meeting, 14th Dynare conference, 2018 Midwest Macro Fall meeting, SEA annual meeting, 2018 RES PhD meeting, 2019 Barcelona Summer Forum for helpful discussions. All errors are my own. 


\section{Abstract}

This paper evaluates the effects of forward guidance and large-scale asset purchases (LSAP) when the nominal interest rate reaches the zero lower bound. I investigate the effects of the two policies in a dynamic new Keynesian model with financial frictions adapted from Gertler and Karadi $(2011,2013)$, with changes implemented so that the framework delivers realistic predictions for the effects of each policy on the entire yield curve. I then match the change that the model predicts would arise from a linear combination of the two shocks with the observed change in the yield curve in a 30-minute window around Federal Reserve announcements, allowing me to identify the separate contributions of each shock to the effects of the announcement. My estimates imply that LSAP was more important in influencing output and inflation than forward guidance.

Topics: Business fluctuations and cycles; Central bank research; Econometric and statistical methods; Interest rates

JEL codes: $E, E 5, G, G 0$ 


\section{Introduction}

Between December 2008 and December 2015, the federal funds rate - that is, the conventional monetary policy instrument of the Federal Reserve, or the Fed - consistently hovered near the zero lower bound (ZLB). To provide a much-needed stimulus to the economy, the Federal Open Market Committee (FOMC) resorted to two unconventional monetary policies at once: forward guidance (FG) and large-scale asset purchases (LSAP). In this paper, I propose a novel method of identifying and estimating the effects of forward guidance and LSAP for each FOMC announcement, reconciling yield curve responses predicted from a macro-finance model with the observed changes in yields in a 30-minute window around the announcement. I quantify each announcement's influence on the macro-economy and separate the contribution from forward guidance and LSAP.

Why do we want to separate the two policies? Because the two policies are usually used together ${ }^{1}$ but they affect the yield curve and the macro-economy via different channels. When the Fed provides forward guidance - that is, communicating to the public about the likely near future course of monetary policy - individuals and businesses will use this information in making decisions about spending and investments. ${ }^{2}$ When the Fed purchases longer-term securities, it offsets the disruption being experienced by private financial intermediaries and supports credit flows from the private intermediaries to the firms. ${ }^{3}$ To better understand the efficacy of each policy and accurately estimate their effects, we first need to identify each type of monetary policy.

How to distinguish forward guidance from LSAP? I build up a macro-finance model based on the work of Gertler \& Karadi (2011, 2013). I introduce a forward guidance shock in the form of an announcement of future shocks to the overnight interest rate rule proposed by

\footnotetext{
${ }^{1}$ For example, on December 16, 2008, the FOMC lowered the target for the federal funds rate to a range from 0 to $1 / 4$ percent and indicated that it expected the target to remain there "for some time". In the same announcement, the Fed announced that it would continue to consider ways of using its balance sheet to further support credit markets and economic activity.

${ }^{2}$ Eggertsson \& Woodford (2003) show that lowering the expected path of policy rates can be highly effective in increasing economic activity and inflation for an economy at the zero lower bound. There is a rapidly growing literature on assessing the effect of forward guidance that has been used during the Great Recession. Important contributions include Campbell et al. (2012), Swanson \& Williams (2014), Gertler \& Karadi (2015), Del Negro et al. (2015), Keen et al. (2016) and Swanson (2021).

${ }^{3}$ Chen et al. (2012) augment a standard DSGE model with segmented bond markets, and Gertler \& Karadi (2011, 2013) provide a framework where limits to arbitrage exist. Most empirical research has focused on analyzing the effects of LSAP on interest rates, output, inflation, term and risk in financial markets, as well as spillover effects in other countries. Using a variety of methodologies, researchers generally agree that LSAP has been effective at lowering long-term interest rates and stimulating economic growth. For example, see Gagnon et al. (2011), Krishnamurthy et al. (2011), Gilchrist \& Zakrajšek (2013), Bauer \& Rudebusch (2014).
} 
Laséen \& Svensson (2011). Also following Gertler \& Karadi (2011, 2013), I model LSAP as the central bank's purchase of a perpetuity. I show both qualitatively and quantitatively that forward guidance and LSAP have the opposite effects on the slope of the yield curve.

Why do we need a structural model? Our ultimate goal is to identify and estimate the dynamic effects of the unconventional monetary policy on the economy. The most common approach in empirical monetary economics literature is to estimate the impulse response of macro variables through a vector autoregression (VAR), as in Christiano et al. (2005), or the local projection (LP) method as proposed by Jordà (2005). However, the LSAP program only began at the end of 2008 and ended in late 2014. Small sample bias will arise and severely distort statistical inference. On the other hand, one can still precisely measure the response of variables that respond to monetary policy shocks contemporaneously, such as financial variables. I use these instantaneous responses to estimate a structural model, an approach pioneered by Nakamura \& Steinsson (2018). The model, which is incorporated with rich features such as habit formation, costs of adjustment in new capital production, financial frictions and multiple financial assets, will generate dynamic responses of macro variables.

What are the major monetary policy transmission channels in the model? In the model, a shadow overnight rate follows a Taylor rule. When a crisis hits the economy, the observed overnight rate endogenously remains at the ZLB for a couple of periods. The Fed announces easing forward guidance policy to keep the overnight rate low in the near future. The policy lowers both current and the near future shadow rates, thus the shadow rate drops more than the perpetuity rate. Households, who face an inter-temporal trade-off between saving and consumption, will consume more and save less as a response. When the Fed purchases the perpetuity, the demand for the perpetuity will increase, the perpetuity rate will drop, financial intermediaries will be less leveraged and firm's borrowing cost will lowered. All of these consequences will raise the market's expectations for output and inflation. If the Fed in the future were to respond to the higher output and inflation with its usual Taylor rule, the result would be sooner lift-off from the zero lower bound and a higher path for the overnight rate. Thus, the model predicts that only using LSAP would lower the perpetuity rate but raise the shadow overnight rate. To recap the identification mechanism, an easing forward guidance shock will increase the slope of the yield curve, while an easing LSAP shock will decrease the slope of the yield curve.

What do we learn from the model? I find forward guidance affects Treasury yields at all maturities, with a peak effect at a maturity of about 20 months. By contrast, LSAP exerts its peak effect on the longest-term maturities but increases short-term maturities. An easing 
forward guidance shock, which lowers the shadow rate by 25 basis points, will increase the current output by 0.02 percent and the current annualized inflation rate by 0.08 percentage points while having little effects on the perpetuity rate. An easing LSAP shock, which lowers the perpetuity rate by 5 basis points, will raise the shadow short-term nominal interest rate by 44 basis points, the current output by 0.1 percent and the current annualized inflation rate by 0.18 percentage points.

What are the sizes of each type of monetary policy shock in each FOMC announcement? I document the unexpected changes in the entire yield curve over a 30-minute window surrounding each announcement. Then I estimate the model so that the changes in the yields that the structural model predicts from a linear combination of the two types of shocks will match the observed changes in yields. This procedure is repeated for each announcement. Figure 1 shows the estimated sizes of each type of monetary policy.

What can we conclude for the dynamic effects on the macro-economy? For each announcement, I simulate the structural model with the estimated sizes of two policies to make inferences about the dynamics of the variables of interest, especially GDP and inflation. Overall, my estimates indicate that the QE I program (from November 2008 to March 2010) increased one year ahead of real GDP by 0.41 percent and one year ahead of expected inflation by 0.24 annualized percentage points. LSAP exerts a greater influence on inflation expectations and output.

My paper makes a number of important contributions to the literature. First, to the best of my knowledge, only Swanson (2021), who mobilized principal component representations of various interest rates, has separated the effects of forward guidance and LSAP on the financial market for each of the Fed's announcements. My paper complements Swanson's (2021) work in the following three aspects: (i) In addition to financial markets, my paper also focuses on forecasting the long-term effects of unconventional monetary policies on real activity. (ii) My paper provides a micro-foundation of the different effects of forward guidance and LSAP on the yield curve. ${ }^{4}$ As discussed in Section 4.6, the implications of the theoretical model echo the empirical findings in Swanson (2021). (iii) Recent literature has increasingly emphasized that the high-frequency measures of monetary policy surprises could be endogenous. For example, Campbell et al. (2012) and Nakamura \& Steinsson (2018)

\footnotetext{
${ }^{4}$ Gertler \& Karadi (2015), for instance, have used external instruments in a structural VAR to identify monetary policy shocks and 1- and 2-year Treasury bond yields as conceptually preferred policy indicators to study the mechanism of the transmission of forward guidance. Earlier, Chung et al. (2012) estimated a structural model that assumes that the term premium of long-term Treasury bonds is inversely proportional to the Fed's holdings of long-term securities. Baumeistera \& Benatib (2013) employed a time-varying parameter structural VAR model under the assumption that LSAP lowers the long-term yield spread while short-term interest rates remain unchanged.
} 
find that the Fed's announcements contain information about economic conditions, whereas Bauer \& Swanson (2020) show that interest rate surprises during the Fed's announcements correlate with the economic news. In line with these papers, I first decompose the highfrequency movement in various interest rates into an endogenous component, which can be explained by the Fed's information set and an exogenous monetary policy stance component. The latter one is further decomposed into forward guidance and LSAP. My estimates show that much of the movement in interest rates comes from the Fed's information; without that distinction, by contrast, the overall effects of unconventional monetary policy on real GDP are three times larger.

Second, there has been a growing literature to study the effects of unconventional monetary policies in a New Keynesian dynamic stochastic general equilibrium (DSGE) model, e.g., Sims \& Wu (2021), Wu \& Zhang (2019) and Ray (2019). This paper contributes by building a micro-founded model and using the model's implications to estimate and forecast the effects of real-time monetary policy announcement.

The third strand of related literature is the use of event study (such as Gagnon et al. (2011) and Krishnamurthy et al. (2011)) to assess the effects of unconventional monetary policies on interest rates. ${ }^{5}$ Instead of using text analysis to discern changes in words and sentences in current FOMC statements compared to previous statements or whether the event date belongs to a certain period of policy implementation, I allow the data to indicate the direction and size of monetary policy. Use of high-frequency data can capture anything the Fed does or fails to do that affects the market. For example, if the Fed chose not to take some action or not to make a change in wording that the market anticipated, ${ }^{6}$ that absence of action can also be interpreted as revealing new information about monetary policy to the market.

Finally, my paper draws from empirical studies on channels used to signal the Fed's bond purchases. Previously, scholars such as Bauer \& Rudebusch (2014) found that such purchases have important signaling effects that lower expected future short-term interest rates by

\footnotetext{
${ }^{5}$ Wright (2012) uses a structural VAR to identify the effects of monetary policy shocks on various long-term interest rates. The VAR is identified using the assumption that monetary policy shocks are heteroskedastic: monetary policy shocks have higher variance on days of FOMC meetings and certain speeches than the other days.

${ }^{6}$ For example, on January 28, 2009, the FOMC statement was interpreted by some market participants as disappointing because of its lack of concrete language regarding the possibility and timing of purchases of longer-term Treasuries in the secondary market contrary to the other announcements (Gilchrist \& Zakrajšek 2013, Bauer \& Rudebusch 2014). As another example, on September 18, 2013, the FOMC was widely expected to begin tapering its asset purchases while it turned out not to do so.
} 
using an event study. My paper provides an alternative explanation for their finding: ${ }^{7}$ an LSAP announcement that causes output and inflation to rise today implies higher interest rates today, particularly via the endogenous component in the central bank's policy rule. Therefore, to keep short-term rates at a low level, policy makers need to reassure the market that the policy rate will be kept low.

The remainder of the paper proceeds as follows. In Section 2, I begin by describing the model, which I calibrate in Section 3 to match the key features of the data, as well as calculate the state-dependent impulse responses in different scenarios. In Section 4, I describe the estimation methodology and results. In Section 5, I discusses several key announcement days. Last, I close the paper in Section 6 by summarizing the findings. The appendices provide additional details about the Fed's announcement.

\section{Structural Model}

The framework is based on the model of Gertler \& Karadi (2011, 2013). They modify a reasonably standard New Keynesian model to explicitly include financial market structure and financial balance sheets. The model makes three primary assumptions. Banks finance risky, long-term assets with riskless, short-term debt. The existence of an agency problem between households and banks constrains the borrowing ability of the latter and generates excess returns between long- and short-term debts. The central bank provides mediation for long-term asset purchases during economic crises and boosts the economy by reducing the credit costs of the banking sector.

I add the following features to their model. First, I introduce a nominal shadow overnight interest rate that I assume follows a Taylor rule subject to the ZLB. The shadow overnight rate is the same as the observed overnight rate when the ZLB is not binding and is negative when the ZLB is binding. Second, I introduce a forward guidance shock as the form of announcement of future shocks to the Taylor rule, the modeling device for generating innovations in expected future interest rates proposed by Laséen \& Svensson (2011). Third, instead of assuming that the one-period nominal interest rate is pegged for a certain length of time as in Gertler and Karadi, the length of time that the economy stays at the ZLB in my model is an endogenous response to the interaction between monetary policy shock and other shocks.

Forward guidance policy lowers both current and the near future shadow rates. The

\footnotetext{
${ }^{7}$ Bhattarai et al. (2015) build a signaling theory where LSAP is effective because it generates a credible signal of low future real interest rates in a time consistent equilibrium.
} 
shadow rate drops more than the perpetuity rate since the forward guidance only lasts a couple of quarters. When the Fed purchases the perpetuity, it would lower the perpetuity rate but raise the shadow overnight rate.

In the following part of this section, I characterize the distinctive elements of the dynamic general equilibrium model, including the behavior of households, banks, producers and the central bank, and a full yield curve interpolation. See Appendix A for the first-order conditions of household's and firm's decision problems and the Online Appendix for thorough expositions of the model.

\subsection{Households}

The economy is populated by a continuum of households of measure unity. Within each household there are two types of members: workers and bankers. A fraction $1-f$ of the household members are workers, and a fraction $f$ are bankers. Workers provide labor and earn wages. Each banker manages a financial intermediary and returns the profit back to the household. Within the family there is perfect consumption insurance.

A banker this period remains a banker next period with probability $\theta$, implying the average survival time for a banker in any given period is $1 /(1-\theta)$. After the bankers exit, their retained earnings return to their respective household in the form of dividends. The bankers who exit become workers and are replaced by a similar number of workers randomly; thus the relative proportion of each type is fixed. New bankers will get startup funds equal to $X_{t}$ provided by the household.

Let $c_{t}$ be consumption and $l_{t}$ labor supply. Then the household's discounted utility $u_{t}$ is given by:

$$
u_{t}=\mathrm{E}_{t} \sum_{j=0}^{\infty} \beta^{j}\left[\ln \left(c_{t+j}-h c_{t+j-1}\right)-\frac{\chi}{1+\phi} l_{t+j}^{1+\phi}\right]
$$

where $\beta \in(0,1)$ denotes the household's subjective discount factor, $h \in(0,1)$ governs the strength of habits and $\chi, \phi>0$. The household's inter-temporal elasticity of substitution is unity, and its Frisch elasticity of labor supply is $1 / \phi$.

There are three types of assets that the household can hold. Households can borrow and lend in a default-free one-period nominal bond market at the nominal interest rate $i_{t}$. Subject to some transaction costs, they can also make private loans to non-financial firms to finance capital to earn the real rate of return $R_{k t}$ and hold a nominal long-term government bond to earn the real rate of return $R_{b t}$. 
Let $S_{h t}$ be the amount of private securities that households have. The transaction cost is equal to the percentage $\frac{1}{2} \kappa_{s}\left(S_{h t}-S_{h}\right)^{2} / S_{h t}$ of the value of the securities in its respective portfolio for $S_{h t}>S_{h}$. Similarly, for government bonds there is a holding cost equal to the percentage $\frac{1}{2} \kappa_{b}\left(B_{h t}-B_{h}\right)^{2} / B_{h t}$ of the total value of government bonds held for $B_{h t}>B_{h}$, where $B_{h t}$ is the amount of long-term government bond that households have.

I define $P_{t}$ as the price level of the consumption good. $Q_{t}$ is the real price of the private securities at time $t$, and $q_{t}$ is the real price of the government bond at time $t$.

Accordingly, at time $t$ the household faces a flow budget constraint in nominal terms:

$$
\begin{aligned}
& P_{t} c_{t}+P_{t} D_{h t}+P_{t} Q_{t}\left[S_{h t}+\frac{1}{2} \kappa_{s}\left(S_{h t}-S_{h}\right)^{2}\right]+P_{t} q_{t}\left[B_{h t}+\frac{1}{2} \kappa_{b}\left(B_{h t}-B_{h}\right)^{2}\right]+P_{t} T_{t}+P_{t} X_{t} \\
& =P_{t} W_{t} l_{t}+P_{t} \Pi_{t}+\left(1+i_{t-1}\right) P_{t-1} D_{h t-1}+P_{t-1} R_{k t} Q_{t-1} S_{h t-1}+P_{t-1} R_{b t} q_{t-1} B_{h t-1} .
\end{aligned}
$$

where $D_{h t}$ is the quantity of one-period nominal bonds held by a household at time $t, T_{t}$ is the lump-sum taxes in real terms, $X_{t}$ is the total transfer the household gives to its members that enter banking at $t, W_{t}$ is the real wage, and $\Pi_{t}$ are the payouts to the household from ownership of both non-financial and financial firms in real terms.

The household's objective is to choose $c_{t}, l_{t}, D_{h t}, S_{h t}$ and $B_{h, t}$ to maximize (1) subject to $(2)$.

Let $\pi_{t} \equiv \frac{P_{t}}{P_{t-1}}-1$ be the inflation rate, then the link between nominal interest rate $i_{t}$ and real interest rate $R_{t}$ is given by the Fisher equation:

$$
1+i_{t}=R_{t}\left(1+\mathrm{E}_{t} \pi_{t+1}\right)
$$

Following Woodford (2001) and other authors (e.g., Arellano \& Ramanarayanan (2012), Chen et al. (2012)), I model the nominal long-term government bond as a depreciating nominal perpetuity that pays a geometrically declining coupon of $\vartheta^{n}$ dollars in each period $n=1,2, \ldots$ after issuance. Let $q_{t}^{n} \equiv P_{t} q_{t}$ be the nominal price of the nominal bond. Then the ex-coupon real rate of return on the nominal bond $R_{b t}$ is given by:

$$
R_{b t}=\frac{1 / P_{t}+\vartheta q_{t}}{q_{t-1}}=\frac{1+\vartheta q_{t}^{n}}{q_{t-1}^{n}\left(1+\pi_{t}\right)}
$$

where the size of the next coupon payment is normalized to one dollar. The very simple recursive structure above makes this type of long-term bond extremely convenient to work with. By choosing $\vartheta$ appropriately, we match the perpetuity's Macauley duration with the corresponding 10-year zero-coupon Treasury bond. 


\section{$2.2 \quad$ Banks}

Banks lend funds obtained from households to non-financial firms and to the government. In addition to acting as specialists that assist in channeling funds from savers to investors, they engage in maturity transformation. They hold long-term assets and fund these assets with short-term liabilities (beyond their own equity capital). Financial intermediaries in this model are meant to capture the entire banking sector, i.e., investment banks as well as commercial banks.

Let $n_{t}$ be the amount of net worth that a banker has at the end of period $t, d_{t}$ the deposits the intermediary obtains from households, $s_{p t}$ the quantity of financial claims on non-financial firms that the intermediary holds, and $b_{t}$ the quantity of long-term government bonds. The intermediary balance sheet is then given by:

$$
Q_{t} s_{p t}+q_{t}^{n} b_{p t}=n_{t}+d_{t}
$$

Net worth is accumulated through retained earnings. It is thus the difference between the gross return on assets and the cost of liabilities:

$$
n_{t}=R_{k t} Q_{t-1} s_{p t-1}+R_{b t} q_{t-1}^{n} b_{p t-1}-R_{t-1} d_{t}
$$

The banker's objective is to maximize the discounted stream of payouts back to the household, where the relevant discount rate is the household's inter-temporal marginal rate of substitution. The terminal wealth is given by:

$$
\mathrm{V}_{t}=\mathrm{E}_{t} \sum_{i=1}^{\infty}(1-\theta) \theta^{i-1} \Lambda_{t, t+i} n_{t+i}
$$

To motivate a limit on the bank's ability to obtain deposits, Gertler \& Karadi (2011) introduce a moral hazard/costly enforcement problem. At the beginning of the period, the banker can choose to divert funds from the assets he holds and transfer the proceeds to the household of which he is a member. The cost to the banker is that the depositors can force the intermediary into bankruptcy and recover the remaining fraction of assets. However, it is too costly for the depositors to recover the funds that the banker diverted. It is assumed that it is easier for the bank to divert funds from its holdings of private loans than from its holding of government bonds: it can divert the fraction $\lambda$ of its private loan portfolio and the fraction $\lambda \triangle$ with $0<\Delta<1$ from its government bond portfolio. Therefore, for depositors to be willing to supply funds to the banker, the following incentive constraint 
must be satisfied:

$$
V_{t} \geq \lambda Q_{t} s_{p t}+\lambda \triangle q_{t}^{n} b_{p t}
$$

The left side is what the banker would lose by diverting a fraction of assets. The right side is the gain from doing so. The banker's maximization problem is to choose $s_{t}, b_{t}$ and $d_{t}$ to maximize (5) subject to (3), (4) and (6).

\subsection{Central Bank's Asset Purchases}

The central bank is allowed to purchase quantities of private loans $S_{g t}$ and long-term government bonds $B_{g t}$. To finance these purchases, it issues risk-free short-term debt $D_{g t}$ that pays the safe market interest rate $i_{t}$. In particular, the central bank's balance sheet is given by:

$$
Q_{t} S_{g t}+q_{t}^{n} B_{g t}=D_{g t}
$$

When limits to arbitrage in the private market are operative, the central bank's acquisition of securities will have the effect of bidding up the prices on each of these instruments and pushing down the excess returns.

\subsection{Aggregation, Production Sector, Fiscal Policy and Equilib- rium}

In this section, I briefly outline the aggregation, the behavior of the production sector (intermediate goods firms, capital goods producers, final goods firms), the fiscal policy, and the equilibrium conditions. These agents' problems are standard. The equations describing the behavior of these agents, as well as the aggregate resource constraint and the marketclearing conditions, are listed in Table 1.

Intermediate goods firms The economy also contains a continuum of infintely-lived monopolistically competitive firms, each producing a single differentiated good. Each operates a constant returns to scale technology with capital and labor inputs and has identical Cobb-Douglas production functions $Y_{t}=A_{t}\left(\xi_{t} K_{t-1}\right)^{\alpha} l_{t}^{1-\alpha}$, where $\xi_{t}$ is a random disturbance that we refer to as a "capital quality" shock. The capital quality shock is a simple way to introduce an exogenous source of variation in the return to capital. It is best thought of as capturing some form of economic obsolescence, as opposed to physical depreciation.

The capital accumulation follows $K_{t}=\xi_{t} K_{t-1}(1-\delta)+I_{t}$. To finance the new capital, 
the firm must obtain funding from a bank. Then by arbitrage, the value of the security is equal to the market price of the capital underlying security: $Q_{t} K_{t}=Q_{t} S_{t}$.

Capital goods producers Capital producers make new capital using inputs of final output and subject to adjustment costs. They sell the new capital to firms at the price $Q_{t}$. Given that households own capital producers, the objective function of a capital producer is $\mathrm{E}_{t} \sum_{j=0}^{\infty} \Lambda_{t, t+j}\left\{Q_{t+j} I_{t+j}-\left[1+f\left(\frac{I_{t+j}}{I_{t+j-1}}\right)\right] I_{t+j}\right\}$.

Final goods firms The output of each firm $s$ is purchased by a perfectly competitive final goods sector, which aggregates the differentiated goods into a single final good using a CES production technology: $Y_{t}=\left[\int_{0}^{1} Y_{t}(s)^{\frac{\epsilon-1}{\epsilon}} d s\right]^{\frac{\epsilon}{\epsilon-1}}$ where $Y_{t}$ denotes the quantity of the final good.

Firms set prices optimally subject to nominal rigidities in the form of Calvo (1983) price contracts, which expire with probability $1-\gamma$ each period. Each time a Calvo contract expires, the firm sets a new contract price freely, which then remains in effect for the life of the new contract.

Government $G_{t}$ is the government spending at time $t$. The supply of long-term government bonds is fixed by the government, $B_{t}=\bar{B}$.

\subsection{Monetary Policy}

I assume the central bank sets the one-period nominal interest rate $i_{t}$ according to the following policy rule,

$$
\begin{aligned}
i_{t}^{*} & =r+\bar{\pi}+\kappa_{\pi}\left(\pi_{t}-\bar{\pi}\right)+\kappa_{y}\left(\log Y_{t}-\log Y_{t}^{*}\right)+z_{t} \\
i_{t} & =\max \left\{\underline{\iota}, i_{t}^{*}\right\}
\end{aligned}
$$

where $\underline{\iota}$ is the lower bound on the one-period nominal interest rate, $i_{t}^{*}$ is the rate the central bank would set if it were unconstrained, $r=-\log \beta$ denotes the steady-state one-period real interest rate, and $Y_{t}^{*}$ is the natural (flexible-price equilibrium) level of output. For simplicity, minus the price markup is used as a proxy for the output gap.

There are two types of unconventional policies: the forward guidance and the asset purchases.

Forward guidance The previous work of Laséen \& Svensson (2011), Del Negro et al. (2015) and Keen et al. (2016) use a combination of current and anticipated monetary policy shocks to model forward guidance shocks. I define $\varepsilon^{m, t} \equiv\left(\varepsilon_{t, t}^{m}, \varepsilon_{t+1, t}^{m}, \ldots, \varepsilon_{t+T, t}^{m}\right)^{\prime}$ as a zeromean i.i.d. random $(T+1)$-vector realized in the beginning of period $t$ and called the 
innovation in period $t . \varepsilon^{m, t}$ can be interpreted as the new information the central bank announces in the beginning of period $t$ about current and future periods. Then for the monetary policy rule at period $t,\left\{\varepsilon_{t, t-j}^{m}\right\}, j=0, \ldots, T$, are all the innovations.

Thus, $z_{t}$, the monetary policy deviation at time $t$, is

$$
z_{t}=\varepsilon_{t, t}^{m}+\sum_{j=1}^{T} a_{j} \varepsilon_{t, t-j}^{m}
$$

for a given $T \geq 0$, where $\varepsilon_{t, t-j}^{m}$ is realized in the beginning of period $t-j$ and called the innovation in period $t . a_{j}$ governs the size of each shock.

In order to determine the magnitude of $a_{j}$, where $j>0$, I follow the specification in Bundick \& Smith (2020) and assume that the series of the size is an exponential decay process, i.e., $a_{j}=\rho_{z}^{j}$ for $j=1, \ldots T$, where $\rho_{z}$ is a constant between 0 and 1 .

Asset purchases In addition to the interest rate monetary policy, the central bank could directly purchase government bonds during a crisis.

When the bank faces balance constraint, given the total quantity of bank equity, an increase in the central bank's holding of long-term government bonds will increase the total demand for private securities. Since asset supplies are relatively inelastic in the short run, the enhanced asset demand pushes up the real price of capital $Q_{t}$ and pushes down the excess return on capital. Furthermore, the presence of inelastic household security demands will strengthen the effects.

Following Gertler \& Karadi (2013), the fraction of central bank holdings of government bonds, $\varphi_{b t} \equiv B_{g t} / B_{t}$, obeys a second-order stationary stochastic process to capture the cumulative buildup of asset purchases program:

$$
\varphi_{b t}=\rho_{0 b}+\rho_{1 b} \varphi_{b t-1}+\rho_{2 b} \varphi_{b t-2}+\varepsilon_{t}^{l s a p}
$$

where $\varepsilon_{t}^{l s a p}$ is the LSAP shock.

\subsection{Yield Curve Interpolation}

There are only two types of yields from the current structural model: the overnight rate and the perpetuity rate. To incorporate more yields at different maturities, one could introduce multiple Treasury bonds at each maturity and specify the risk premium of each bond. For example, to have a ten-year bond in a quarterly dynamic model, we also need to introduce another 39 bonds that mature after 1, 2, .., 39 quarters, respectively, and we 
also need to calibrate the steady-state of risk premium for these bonds. In this section, I introduce an alternative method that provides a flexible approximation to interpolate the full yield curve using the overnight shadow rate and the perpetuity rate implied by the structural model. The details can be found in Appendix B.

Ang et al. (2006) find that at most two factors are needed to capture almost all of the variation of yields at a quarterly frequency. I assume that two possibly unobserved factors, $\left(\xi_{1 t}, \xi_{2 t}\right)$, summarize everything that matters for determining interest rates. Their Q-measure dynamics are characterized by:

$$
\begin{aligned}
& \xi_{1 t}=\phi_{1} \xi_{1 t-1}+\varepsilon_{1 t} \\
& \xi_{2 t}=\phi_{2} \xi_{2 t-1}+\varepsilon_{2 t}
\end{aligned}
$$

The one-period nominal interest rate $i_{t}$ is equal to $i_{t}^{*}$ if $i_{t}^{*}>\underline{\iota}$, and equal to $\underline{\iota}$ otherwise, where the shadow rate $i_{t}^{*}$ follows:

$$
i_{t}^{*}=\xi_{1 t}+\xi_{2 t}
$$

When $\phi_{1}=1$ and $\left|\phi_{2}\right|<1$, Wu \& Xia (2016) demonstrate that in equilibrium, the forward rates $f_{n t}$ can be approximated as:

$$
\begin{aligned}
& f_{n t}^{*}=\xi_{1 t}+\phi_{2}^{n} \xi_{2 t} \\
& f_{n t}=\underline{\iota}+\sigma_{n} g\left(\frac{f_{n t}^{*}-\underline{\iota}}{\sigma_{n}}\right)
\end{aligned}
$$

where $g(z)=z \Phi(z)+\phi(z)$, with $\Phi(z)$ as the cumulative distribution function for a standard Normal variable, $\phi(z)$ as the density, and $\sigma_{n}$ as a parameter.

The yield at date $t$ with maturity $n$ is:

$$
i_{n t}=n^{-1} \sum_{j=0}^{n-1} f_{j t}
$$

Equations (8) and (11) allow us to recover the two factors directly off the level of the oneperiod shadow rate $i_{t}^{*}$ and the long-term rate $i_{N t}$. Then we can recover $i_{n t}$ at any maturity $n$ applying the two factors in equations (9), (10) and (11). 
Furthermore, we define the risk-neutral rate $i_{n t}^{R N}$ and risk premium $i_{n t}^{T P}$ as follows:

$$
\begin{aligned}
& i_{n t}^{R N}=\sum_{j=0}^{n} i_{t+j} \\
& i_{n t}^{T P}=i_{n t}-i_{n t}^{R N}
\end{aligned}
$$

\section{Calibration and Simulation of the Structural Model}

In this section, I provide numerical simulations to illustrate the effects of forward guidance and LSAP on macro and financial variables in a ZLB environment. The paper's key identification, i.e., the effects of one-unit FG and one-unit LSAP on the entire yield curve, is derived in subsection 3.3 and displayed in Figure 5.

\subsection{Calibration}

Table 2 lists the choice of parameter values for the model. I begin with the parameters that have the same values as in Gertler \& Karadi (2013). These are shown in Panel (A). I assign a quarterly value of 0.995 , which implies a short-term real interest rate of 2 percent. The habit parameter, $h$, is 0.65 . The depreciation rate of capital $\delta$ is set to be 0.025 , and the capital share $\alpha$ is 0.33 . The price rigidity parameter $\gamma$ is 0.779 , which implies firms resetting prices approximately every 13.6 months on average. The degree of price indexation $\gamma_{p}$ is assumed to be zero. The inverse elasticity of investment with respect to the price of capital, $\eta_{i}$, is 5.17. The steady-state leverage ratio is 6 as in GK's 2013 paper (4 in their 2011 paper). The steady-state government expenditure share $G_{s s} / Y$ is 0.2 , and the steady-state labor is $1 / 3$. $\phi_{y}=-0.125$ for the Taylor rule coefficient on output gap. I set $\bar{K}_{h}$ so that in steadystate, households hold half the quantity of private securities, and $\bar{B}_{h}$ so that households hold three-quarters of the outstanding stock of long-term government debt. $\bar{B}$ is set such that the ratio of the stock of long-term government bonds to output in steady-state is equal to its pre-crisis value of approximately 0.45 . The AR(2) coefficients for the LSAP shock are 1.5 and -0.55 .

However, some of the other parameters used by GK imply properties of the yield curve and the relation between bond and stock yields that are inconsistent with the observed data. Since interpreting the response of the yield curve to shocks is the focus of the present exercise, I have made a number of changes so that the predictions of the model better match the properties observed in financial data. 
Panel (B) shows the parameters that are closely related to yield curve properties. GK assume an inflation target $\bar{\pi}=0$. To match the average values of the nominal interest rate in the pre-ZLB data from Gürkaynak et al. (2007) dataset, I set $\bar{\pi}=0.006$, corresponding to an annual inflation target of 2.4 percent. Thus the steady-state value of the nominal interest rate is 4.4 percent. GK assume a lower bound of 0 in their original calibration. But the short end of the yield curve was never literally zero, with excess reserves earning 0.25 percent interest from the Fed throughout this period. For this reason, I set $\underline{\iota}=0.25$ percent.

The other parameters in Panel (B) matter for the steady-state bond excess return and equity excess return. GK set the steady-state real excess return on long-term government bonds to be 50 basis points and real excess return on private securities to be 100 basis points. Since there is no observed series for the real interest rate on an overnight government bond, I use the 2-year inflation-indexed Treasuries (TIPS) yield instead. Taken from the updated Gürkaynak et al. (2010) online dataset, from 2004 to 2007 the average difference between a 10-year TIPS and a 2-year TIPS is 69 basis points, ${ }^{8}$ which is much larger than GK's implied spread of 33 basis points. By contrast, my parameters imply a predicted spread that is exactly equal to 69 basis points. For the private securities, I follow GK and use the information on pre-2008 spreads between mortgage rates and the 10-year Treasury yield and between BAA corporate and the 10-year Treasury yield. Using data from the St. Louis Federal Reserve Economic Database (FRED), I find that on average the former is 163 basis points and the latter is 353 basis points from January 1990 to November 2008. ${ }^{9}$ Therefore, I set the steady-state excess return on private securities to be 172 basis points, higher than the 100 basis points in GK.

The expected horizon for bankers, the steady-state leverage ratio, together with the two excess return values mentioned above, pin down $\theta, \lambda, \Delta$ and $X$, where the parameter $\lambda$ is the percent of funds that a banker can divert to his household. $\lambda$ is $38.1 \%$ equal to the value used in GK's 2011 paper. Since I have adjusted the excess return values, the expected horizon for bankers is 5.7 years.

The remaining part of Panel (B) is the household's portfolio adjustment cost parameters $\kappa_{s}$ and $\kappa_{b}$. These parameters are chosen to make the predicted effects of LSAP on mediumterm bond yields more consistent with the data during the crisis. Since I have made the

\footnotetext{
${ }^{8}$ Following Swanson (2015), I use the 2004-2007 period to avoid both the low liquidity of TIPS in its first few years and the financial crisis and recession. Over this sample, real yields average between about 1.4 percent and 2.1 percent.

${ }^{9}$ Another way is to look at the relative size of the two excess returns, as represented by the parameter $\triangle$. The average ratio of the spread between the 10-year Treasury yield and the federal funds rate over the spread between BAA and the federal funds rate is 0.29 while the spread between the 30 -year mortgage rate and the federal funds rate is 0.87 . My calibration implies 0.6.
} 
above changes, I also have to make adjustments for those parameters. The values are chosen by searching over a wide range of values to find the best possible fit of the model to the data.

Panel (C) presents other parameters used by GK that differ substantially from previous studies and raise the possibility of some odd dynamics of the model. I have found that the model is much more realistic when more conventional values are used for these parameters. GK assume a value for $1 / \phi$, the Frisch labor supply elasticity, equal to 3.6. I instead set $1 / \phi=2$. GK assume an elasticity of substitution $\varepsilon$ between goods of 4.167 , implying a steady-state markup of $31.58 \%$. My exercise sets $\varepsilon=6$, implying a more realistic markup of $20 \%$. The coefficient for the Taylor rule $\phi_{\pi}$ is taken from Coibion et al. (2012).

Finally, there are four parameters that are new to my model, $\rho_{z}, \vartheta, \phi_{2}$ and $\sigma_{n} . \rho_{z}$ governs the decaying behavior of the forward guidance shock; I choose it equal to 0.65 . $\vartheta$ is chosen so that the Macauley duration of the perpetuity is 7.5 years. $\phi_{2}$ and $\sigma_{n}$ are chosen to match the pre-ZLB and ZLB average yield curve. Details are in Appendix B.

\subsection{Crisis Simulation}

I now explore how the unconventional monetary policy works in the context of a financial crisis as described in Gertler \& Karadi (2011, 2013). The initiating shock for the crisis is a decline in capital quality. It forces the asset prices to decline and the excess return of capital to rise, which depresses real activity and in turn amplifies the downturn. Furthermore, the drops of output and inflation are sufficiently sharp to push the economy to the point where the nominal interest rate hits the zero lower bound.

I suppose that the capital quality shock obeys a first-order autoregressive process with coefficient 0.88. In the baseline calibration, the size of the initial shock is chosen to lower the nominal shadow rate to negative 121 basis points on impact, along with three quarters of zero lower bound episodes.

Solution Method I solve the model using the OccBin toolkit developed by Guerrieri \& Iacoviello (2015). The solution method constructs a piecewise linear approximation to the

original nonlinear model. It allows us to model the occasionally-binding zero lower bound and solve for the short-term and long-term yields.

Figure 2 shows the dynamic responses of the excess return of capital; inflation; output; the overnight, 3-month, 6-month, 2-year, 5-year and 10-year yields; 10-year risk neutral rate; and term premium to a negative capital quality shock. The initial decrease of capital quality drives up the real excess return of capital. The process is amplified as the asset fire sale and decline in real activity further weaken banks' balance sheets. The existence of the zero lower 
bound will make the recession more severe. The real output drops almost 3 percent at the peak, and the annual inflation rate drops 2 percentage points initially.

\subsection{Effects of a One-Unit Monetary Policy Shock}

We now turn to the interventions by the central bank. First, I need to choose the forward guidance horizon $T$. It must be longer than the ZLB episodes' length to allow the monetary policy to provide stimulus and at the same time be a realistic and credible commitment horizon made by the central bank. It is set to last seven quarters in the baseline.

I also need to choose the scale of the monetary policy shocks. Since the traditional monetary policy literature usually defines one unit of easing monetary policy shock, such as lowering the federal funds rate by 25 basis points, in the ZLB scenario I consider here it's natural to define that one unit of easing forward guidance shock is to lower the nominal shadow rate by 25 basis points on impact. I define that one unit of easing LSAP shock will lower the 10-year Treasury yield by 5 basis points on impact.

The forward guidance policy shock is a series of shocks $\left\{\varepsilon_{t, t}^{m}, \varepsilon_{t+1, t}^{m}, \ldots, \varepsilon_{t+T, t}^{m}\right\}$ to the path

of the future shadow rates. I set each element of $\left\{\varepsilon_{t, t}^{m}, \varepsilon_{t+1, t}^{m}, \ldots, \varepsilon_{t+T, t}^{m}\right\}$ to change by the same amount $\varepsilon^{f g}$ and look at the effects on the other variables. With the parameter calibration described in Section 3.1, this requires to $\varepsilon^{f g}=-0.0013$. As for LSAP shock, $\varepsilon_{t}^{\text {lsap }}$ in equation (7) is set to be 0.07 such that the 10-year yield is lowered by 5 basis points on impact.

In Figures 3 and 4, I plot the differences an easing unconventional monetary policy, forward guidance and LSAP respectively, made to the response of the financial variables and macro variables in addition to the negative capital quality shock. A one-unit easing forward guidance shock will increase the current output by 0.02 percent and the current annualized inflation rate by 0.08 percentage points. A one-unit easing LSAP shock will raise the shadow short-term nominal interest rate by 28 basis points, the current output by 0.09 percent, and the current annualized inflation rate by 0.12 percentage points.

Figure 5 shows the paper's key identification. It illustrates the yield curves' response to one unit of easing policy interventions. As shown in the figure, one unit of easing forward guidance lowers Treasury yields at all maturities, with a peak effect at a maturity of about 20 months. In contrast, one-unit easing LSAP will increase the shortest-maturity Treasury yields due to the feedback of the interest rate rule but will lower long-term yields, with the 
peak effect on the longest maturities. ${ }^{10}$

\section{Decomposition of the Federal Reserve's Announce- ment}

So far, I have shown the effects of one-unit monetary policy shocks implied by the theory. But how large are the effects on the macro-economy and financial market implied by the FG and LSAP policies announced by the FOMC? In order to answer this very important practical question, in this section I match the change that the model predicts would arise from a linear combination of the two shocks with the observed change in the yield curve in a 30-minute window around Federal Reserve announcements, allowing me to identify the separate contributions of each shock to the effects of the announcement.

As many studies on high-frequency identification assume, the movements of Treasury yields on various horizons in a narrow window that brackets the Fed's announcement days are responses to the Fed's announcements only. The Fed could surprise the markets (i) by announcing a monetary policy path deviating from the private sector's previous expectations, (ii) by announcing an asset purchase program that also deviates from the private sector's previous expectations, or (iii) by shaping the private sector's beliefs about economic conditions. I refer to (i) as forward guidance and (ii) as LSAP, both of which are exogenous monetary policy deviations, whereas I refer to (iii) as the information effects as documented in recent literature, e.g., Campbell et al. (2012), Nakamura \& Steinsson (2018), Cieslak \& Schrimpf (2019) and Jarociński \& Karadi (2019).

\subsection{Estimation Method to Isolate Monetary Policy Stance}

To isolate the pure monetary policy stance shock (i) and (ii) from the belief updating, I use Romer \& Romer (2004), Miranda-Agrippino \& Ricco (2018) and Zhang (2018)'s methods and regress the observed changes of yields at each maturity on the Greenbook projections. In

\footnotetext{
${ }^{10}$ To make the magnitude of easing and tightening policies comparable, one unit of tightening forward guidance is defined to increase the nominal shadow rate by 25 basis points and one unit of tightening LSAP to increase the 10-year Treasury yield by 5 basis points. However, there are asymmetric responses due to the existence of the ZLB. A tightening LSAP shock lowers the shadow rate further, which leads the economy to stay at the ZLB longer than the easing case. Meanwhile, the tightening forward guidance shock lifts the shadow rate but not enough to reduce the ZLB length. The magnitude for $\varepsilon^{m, t}$ won't change. But a slightly smaller $\varepsilon_{t}^{b}$ compared to the values for the easing policies is chosen to accommodate the asymmetric responses.
} 
particular, I estimate the following equation for each yield at maturity $n \in\{3$-month $(0.25)$, 6-month(0.5), 2-year(2), 5-year(5), 10-year(10)\}:

$$
\begin{aligned}
\triangle i_{n t} & =\beta_{n 0} i_{n t^{-}}+\sum_{j=-1}^{s(n)} \beta_{n j}^{\triangle \mathrm{INFL}} \triangle \mathrm{INFL}_{t, q(t)+j}^{\mathrm{GB}}+\sum_{j=-1}^{s(n)} \beta_{n j}^{\triangle \mathrm{RealGDP}} \triangle \operatorname{RealGDP}_{t, q(t)+j}^{\mathrm{GB}} \\
& +\sum_{j=-1}^{s(n)} \beta_{n j}^{\mathrm{INFL}} \mathrm{INFL}_{d, q(t)+j}^{\mathrm{GB}}+\sum_{j=-1}^{s(n)} \beta_{n j}^{\mathrm{RealGDP}} \operatorname{RealGDP}_{t, q(t)+j}^{\mathrm{GB}} \\
& +\beta_{n 0}^{\mathrm{UNEMP}} \mathrm{UNEMP}_{t, q(t)}^{\mathrm{GB}}+\text { constant }+\varepsilon_{n t}
\end{aligned}
$$

where $\triangle i_{n t}$ is the observed 30-minute change in the interest rate of maturity $n$ around announcement on day $t$; and $i_{n t}$ is the level of the interest rate before any changes associated with the announcement, which is included to capture any tendency toward mean reversion in the Fed's behavior. Let $q(t)$ be the quarter when the announcement day $t$ takes place. $\mathrm{INFL}_{t, q(t)+j}^{\mathrm{GB}}$ and RealGDP $\mathrm{GB}_{t, q(t)+j}$ denote Greenbook projections for inflation and real GDP growth for quarter $q(t)+j$ made at event day $t, j=-1,0, \ldots, s(n)$, respectively. The maximum

length of forecast horizons, $s(n)$, is equal to two-, two-, three-, four-, and four-quarter ahead for $n=0.25,0.5,2,5$ and 10. $\triangle \mathrm{INFL}_{t, q(t)+j}^{\mathrm{GB}}$ and $\triangle \mathrm{RealGDP}_{t, q(t)+j}^{\mathrm{GB}}$ is the revised forecast for inflation and real GDP growth rate between two consecutive events, respectively. In computing the forecast innovations, the forecast horizons for event $t$ and $t-1$ are adjusted so that the projections refer to the same quarter.

The information components of 3-month and 6-month yields after December 2008 are set to zero, i.e., $\triangle i_{n t}^{m p}=\triangle i_{n t}$.

The fitted value of the each regression, $\triangle i_{n t}^{i n f o}$, approximate the change caused by the Fed's superior information, while the residuals of each regression, $\triangle i_{n t}^{m p}$, is the monetary policy stance component.

\subsection{Simulated Method of Moments to Disentangle FG and LSAP}

I now use the simulated method of moments to decompose the monetary policy stance shock into a forward guidance component and an LSAP component. The two unknown parameters to estimate are $\epsilon_{t}^{f g}$ and $\epsilon_{t}^{l s a p}$.

The empirical target moments are the responses of five different interest rates to monetary policy stance, i.e., $\triangle i_{n t}^{m p}=\left(\triangle i_{0.25 t}^{m p}, \triangle i_{0.5 t}^{m p}, \triangle i_{2 t}^{m p}, \triangle i_{5 t}^{m p}, \triangle i_{10 t}^{m p}\right)^{\prime}$.

The interest rates in the structural model are nonlinear functions of the structural shocks. 
If the central bank announces unconventional monetary policies $\left(\epsilon_{t}^{f g}, \epsilon_{t}^{l s a p}\right)$ at the beginning of the crisis, the effects on the yield curve are $\triangle i_{n}\left(\epsilon_{t}^{f g}, \epsilon_{t}^{l s a p}\right)=\left(\triangle i_{0.25}\left(\epsilon_{t}^{f g}, \epsilon_{t}^{l s a p}\right), \triangle i_{0.5}\left(\epsilon_{t}^{f g}\right.\right.$, $\left.\left.\epsilon_{t}^{l s a p}\right), \triangle i_{2}\left(\epsilon_{t}^{f g}, \epsilon_{t}^{l s a p}\right), \triangle i_{5}\left(\epsilon_{t}^{f g}, \epsilon_{t}^{\text {lsap }}\right), \triangle i_{10}\left(\epsilon_{t}^{f g}, \epsilon_{t}^{l s a p}\right)\right)^{\prime}$. Figure 5 is a special case when $\left(\epsilon_{t}^{f g}\right.$, $\left.\epsilon_{t}^{\text {lsap }}\right)$ are chosen such as $\triangle i^{*}\left(\epsilon_{t}^{f g}, 0\right)=-0.25$ and $\triangle i_{10}\left(0, \epsilon_{t}^{\text {lsap }}\right)=-0.1$.

For each event day $t$, I solve the model numerically and compute the model-implied $\left(\epsilon_{t}^{f g}\right.$, $\epsilon_{t}^{\text {lsap }}$ ) to minimize the loss function, which is quadratic in the difference between $\triangle i_{n t}^{m p}$ and their theoretical counterparts in the model $\triangle i_{n}\left(\epsilon_{t}^{f g}, \epsilon_{t}^{l s a p}\right)$. This procedure is repeated for each of the announcement days.

$$
\min _{\epsilon_{t}^{f g}, \epsilon_{t}^{l s a p}}\left(\triangle i_{n}\left(\epsilon_{t}^{f g}, \epsilon_{t}^{l s a p}\right)-\triangle i_{n t}^{m p}\right)^{\prime} *\left(\triangle i_{n}\left(\epsilon_{t}^{f g}, \epsilon_{t}^{l s a p}\right)-\triangle i_{n t}^{m p}\right)
$$

\subsection{Data}

I obtained FOMC meeting dates between July 1991 and December 2004 from the appendix in Gürkaynak et al. (2005) ${ }^{11}$ and all remaining scheduled/unscheduled FOMC meetings from the Federal Reserve Board's website. In particular, there were 59 event days from November 2008 to December 2014, which are listed in Column 1 in Table 3. I follow the literature and group the announcement dates into the following six phases: QE I phase (November 2008 to March 2010), QE II phase (November 2010 to June 2011), "Operation Twist" phase (September 2011 to August 2012), QE III phase (September 2012 to May 2013), "Tapering" phase (June 2013 to October 2014) and Post QE phase (December 2014 to December 2015), respectively. ${ }^{12}$ Although some of the phases' names are associated with $\mathrm{QE}$, there were explicit forward guidance policy announcements in those periods as well.

I downloaded the Greenbook data from the Philadelphia Fed website. ${ }^{13}$. Because Greenbook data ar released approximately five years later than the meeting day, the latest data that I could access represent December 2015. The intraday change in the Treasury yields are obtained from the Federal Reserve.

\footnotetext{
${ }^{11}$ As stated in their paper, prior to 1994 , the FOMC did not explicitly announce changes in its target for the federal funds rate, but such changes were implicitly communicated to financial markets through the size and type of open market operation. Therefore, they define a monetary policy announcement date to be the one of the next open market operation following the FOMC decision.

${ }^{12}$ The categorization of QE I, QE II, "Operation Twist" and QE III comes from Wu (2014).

${ }^{13}$ https://www.philadelphiafed.org/research-and-data/real-time-center/greenbookdata/philadelphia-data-set. The dataset is updated annually, usually in April.
} 


\subsection{Estimation Result}

First, I use equation (12) to decompose $\triangle i_{n t}, n=0.25,0.5,2,5,10$, into information component $\triangle i_{n t}^{\text {info }}$ and the monetary policy component $\triangle i_{n t}^{m p}$. Due to the financial crisis and the policy actions, the short-term yields were closer to zero and had little variation during the ZLB period. Thus I choose the data sample periods to end in December 2008 for the 3-month yield, March 2010 for the 6-month yield, and December 2015 for the rest.

The R-square statistics are $0.17,0.17,0.18,0.23$ and 0.29 , respectively. This suggests that a substantial fraction of interest rate surprises could be explained by the Fed's forecasts of future growth and inflation. The upper panel of Figures 6 and 7 plots the two components for 5-year and 10-year Treasury yields between November 2008 and December 2015, respectively. On average more than one-fifth of the change in 5-year and 10-year yields come from the information component, especially for the early recession period.

Next, I decompose $\triangle i_{n t}^{m p}$ through the target moments matching. I normalize the estimates $\hat{\epsilon}_{t}^{f g}$ and $\hat{\epsilon}_{t}^{l s a p}$ according to the definition of "units" in Section 3.2: one-unit easing/tightening forward guidance shock lowers/increases the nominal shadow rate by 25 basis points on impact; and one-unit easing/tightening LSAP shock lowers/increases the 10-year yield by 5 basis points on impact. The normalized estimates are $\bar{\epsilon}_{t}^{f g}=\hat{\epsilon}_{t}^{f g} / \epsilon^{f g}$ and $\bar{\epsilon}_{t}^{l s a p}=\hat{\epsilon}_{t}^{l s a p} / \epsilon^{l s a p}$ and are plotted in Figure 1. The vertical axis charts the units. A negative number means easing policy, and a positive number means tightening policy. Unsurprisingly, forward guidance and LSAP policies announced on the same day always work in the same direction, tightening or easing the market. Among all event dates, the QE I announcements have the greatest effects.

The lower panel of Figure 7 plots $\triangle i_{10}\left(\hat{\epsilon}_{t}^{f g}, 0\right)$ and $\triangle i_{10}\left(0, \hat{\epsilon}_{t}^{l s a p}\right)$, the contribution by forward guidance and asset purchases to 10-year yield changes over time. The cumulative effects over the certain policy phases are shown at the end of each section in Table 3 . In QE I phase, the cumulative drop in 10-year Treasury yields in the key announcement dates was 41 basis points: 31 basis points contributed by information effects while 10 basis points by monetary policy component. Forward guidance explained almost 2 basis points and the LSAP 10 basis points.

What shapes of yield curve changes drive the results in Figure 1? Suppose the economy is away from the ZLB and the observed yield curve is exactly linear in the two factors and thus linear in two yields. Easing forward guidance lowers both short-run and long-run yields; LSAP raises the short-term yield and lowers the long-term yield. If we observe there's a drop in both short- and long-term yields, it must come from an expansionary forward guidance 
announcement. On the other hand, if the short-term yield increases and long-term yield decreases, there must be an expansionary LSAP announcement.

\subsection{Dynamic Effects on Macro Variables}

The next goal is to look at the extent monetary policy has fostered economic growth and inflation stability. I simulate the structural model described in Section 2 by a forward guidance shock of $\hat{\epsilon}_{t}^{f g}$ as well as an LSAP shock of $\hat{\epsilon}_{t}^{l s a p}$. This procedure is repeated for each of the announcement days.

The last 4 columns of Table 3 show the effects on GDP and inflation that the model predicts would occur one year after each shock for each event day. The change in real GDP growth is measured by percent, and change in inflation is measured by annualized percentage points.

To quantify the overall effects of the QE I program, I sum the 30-minute change of the monetary policy components over all the QE I event days. I then re-estimate the problem stated in Section 4.2 and simulate the structural model using the estimated shocks. I find that the QE I increased one-year-hence real GDP by 0.41 percent and one-year-hence inflation rate by 0.24 annualized percentage points. I conclude that LSAP have more effects on both output and inflation.

\subsection{Discussion}

Robustness of the Structural Model Simulation In Section 3.2, I've simulated the model so that the initial capital quality shock decreases the shadow rate to negative 121 bps to match the average shadow rate in the ZLB period. The persistence of the forward guidance shock is set to 0.65 , and the forward guidance horizon is seven quarters. I've defined that one unit of an easing LSAP shock will lower the 10-year yield by 5 basis points.

In Appendix Figure B.1, I show that the identification of FG and LSAP is robust to these settings. The upper left panel plots the variation of the difference in the yield curves when the initial shock changes from negative 60 bps to negative 180 bps. A weaker economy skews the LSAP more effectively. The upper right panel shows the differences in the yield curve when the persistence of the forward guidance shock increases from 0.6 to 0.7. Intuitively, a more persistent forward guidance shock is more effective on the 10-year interest rate. The lower left panel is for whether the horizon is six quarters or eight quarters. The lower right

panel shows how the difference in the yield curve varies when I define a one-unit LSAP shock to change the 10-year yield by 3 bps or by 15 bps. 
These model specifications will impact the efficacy of the two types of monetary policies. But the easing LSAP still lowers the spread between long- and short-term yields, while easing forward guidance increases the spread. My findings on the relative size of the two policies' effects on yield curves and the macro-economy will only be slightly affected.

Estimation without 3-Month T-bill The estimation results in Section 4.4 use 3month, 6-month, 2-year, 5-year and 10-year interest rates to estimate the two parameters $\varepsilon_{t}^{f g}$ and $\varepsilon_{t}^{l s a p}$. In the data, the 3-month T-bill rate was almost flat close to zero during the ZLB. I redo the estimation without the 3-month rate. Appendix Figure B.2 compares the SMM estimates. The correlations are almost equal to 1 for both the forward guidance and the LSAP.

The Importance of Isolating the Monetary Policy Stance Previous literature has provide strong support for monetary non-neutrality. For example, using data from 1995 to 2014, Nakamura \& Steinsson (2018) find that roughly two-thirds of the response of real interest rates to FOMC announcements are through the information channel. A recent paper by Bauer \& Swanson (2020) proposes an alternative explanation that the Fed responds to the macro news preceding the announcement and the market participants learn the Fed's response function over time. Whether it's due to information effects or the Fed's response to macro news, there's an endogenous component of the 30-minute window change in interest rates. We need to control for it to make causal inferences about macro variables (Bauer \& Swanson 2020).

To illustrate how allowing for the endogenous part affects my estimates, I re-estimate $\hat{\epsilon}_{t}^{f g}$ and $\hat{\epsilon}_{t}^{l s a p}$ using the original yield curve change $\triangle i_{n t}$ as the target moments. As shown in Figure B.3, the magnitude of $\hat{\epsilon}_{t}^{f g}$ and $\hat{\epsilon}_{t}^{l s a p}$ almost double. The macroeconomic effects will also double if we don't control for the information component.

The Importance of Using Intraday Data All the results shown in Section 4.4 are estimated using 30-minute changes in the Treasury yields. The potential concern of using daily change, as pointed in Gürkaynak et al. (2005), is that there were some other major events occurring on the announcement day and confounding the identification.

If we compare the high-frequency data with daily data, on 11 out of the 59 event days they move in the opposite direction. The correlations between estimates using intraday data and daily data are still positive: 0.64 for the forward guidance and 0.67 for the LSAP. As shown in Figure B.2, the magnitude of $\hat{\epsilon}_{t}^{f g}$ and $\hat{\epsilon}_{t}^{\text {ssap }}$ almost double.

Relationship with Swanson (2021)'s Shock Series Swanson (2021) separately identifies the forward guidance and LSAP shocks using an econometric methodology and studies the effects of each unconventional monetary policy on financial markets. In particular, his 
paper computes the first three principal components of various asset price $^{14}$ responses in a 30-minute window around FOMC announcements and then rotates the three principal components such that the new factors correspond to the change in the federal funds rate, forward guidance and LSAP.

The correlation of the forward guidance shock identified in this paper with Swanson's forward guidance shock is 0.72 , and the correlation of the LSAP shock is 0.8 .

There are a couple of reasons why these two measures are still different. First, Swanson (2021) focusing on estimating, comparing and contrasting a "total forward guidance" effect and a "total LSAP" effect. In this paper, I first isolate the monetary policy stance from the endogenous component (either due to the "information effect" or the Fed's response to macro news), and then separate the forward guidance and LSAP components. This endogenous component explains an ineligible fraction of the interest rate movements, and is larger for 10year rate than for 2-year rate (R-squared statistic 0.29 vs. 0.18). Second, the three principal components in Swanson's paper are rotated under the identifying assumptions that forward guidance and LSAP have no effect on the current federal funds rate and the variance of the LSAP factor is as small as possible over the sample from 1991 to 2008.

I keep the forward guidance shock definition unchanged and follow Swanson's LSAP definition of an LSAP shock. The new LSAP shock is a combination of the forward guidance shock and the original structural LSAP shock such that the shadow rate is not affected by this policy and the perpetuity rate drops five basis points on impact.

Figure 8 plots the effects of the rotated LSAP policy on the yield curve. The structural model predicts that the new LSAP shock affects the full yield curve, and the effects increase as maturities increase with the peak effect on the 10-year Treasury yield. This is consistent with the empirical findings from Swanson (2021).

This rotation won't change the total effects of the unconventional monetary policies on macro variables. It will shift some of the original FG's contribution to the rotated LSAP. Given our conclusion is already that FG contributes less than LSAP, the rotation will make the contribution of LSAP even larger.

If I use the total change $\triangle i_{n t}$ as the target moments, then the estimated shock sizes' correlation with Swanson's shocks are 0.77 and 0.86 , and if in addition I use the rotated shocks such that the shadow rate doesn't change in response to an LSAP shock, the correlation increases to 0.91 and 0.86 , respectively.

\footnotetext{
${ }^{14}$ The asset prices include federal funds futures (the current-month contract rate and the contract rates for each of the next six months), Eurodollar futures (the current-quarter contract rate and the contract rates for each of the next eight quarters), Treasury bond yields (the 3-month, 6-month and 2-, 5-, 10-, and 30-year maturities), the stock market (S\&P 500) and exchange rates (yen/dollar and dollar/euro).
} 
Alternative Explanation of LSAP's Signaling Effects Bauer \& Rudebusch (2014) found that LSAP has important signaling effects that lower expected future short-term interest rates. In the theory papers that QE works, e.g., Gertler \& Karadi (2011), Gertler \& Karadi (2013) and Chen et al. (2012), an easing LSAP shock is a structural shock to the bond purchase process and will lower the 10-year rate, increase output and inflation and thus will always lift the federal funds rate through the Taylor rule in absence of the ZLB. My paper provides a theoretical explanation for their finding: a pure LSAP shock will impose upward pressure for the short-term rate; policy makers need to announce that they intend to keep the short-term rate low for a while, i.e., easing forward guidance.

\section{A Closer Look at Several Key Announcement Days}

Among all the event days, there are several key announcements widely discussed both on the policy side and in academia. In this section, I take a closer look at those days in chronological order, comparing my identification with the relevant FOMC statement and the financial market commentary in The Wall Street Journal as in Gürkaynak et al. (2005). The full list of the event dates with my compilation of relevant statements and the language that is pertinent to forward guidance and LSAP policies are shown in Appendix Table B.1.

\subsection{QE I Phase (November 2008 to March 2010)}

The "QE I" program began on November 25, 2008. The Federal Reserve Board made two announcements on this day. One is that it would initiate a program to purchase $\$ 500$ billion of mortgage-backed securities and $\$ 100$ billion of agency debt and the other is the creation of the Term Asset-Backed Securities Loan Facility (TALF), which would offer oneyear financing. The financial markets were optimistic of these lending facilities to prevent deflation (The Wall Street Journal 2008a) and bring back mortgage-debt buyers (The Wall Street Journal 2008b). Even though there was no explicit words about the forward guidance policy, I argue, as in Bauer \& Rudebusch (2014), that LSAP announcements may signal to market participants that the central bank has changed its views on current or future economic conditions, which leads investors to alter their expectations of the future path of the policy rate. According to the structural model, an easing LSAP policy will drive up output and inflation in the near term, to which the interest rate rule would respond with higher short-term rates in the near future. Therefore, the Fed needs to communicate to the public that it is not its intention to raise the short-term rate in response to the higher 
inflation and output that LSAP is expected to generate. This argument justifies why the LSAP is always used together with forward guidance, as shown in Figure 1. Based on the way the yield curve responded, I have identified that there was easing forward guidance as well as LSAP on November 25, 2008. The overall effect of the two types of policies is lowering the whole yield curve. The Figure 9 shows the dynamic effects of the forward guidance shock and LSAP. The bottom panels show the impulse responses of output and inflation for the current and next eight quarters. As for real GDP, LSAP plays an important role in lifting the growth path. Forward guidance has similar effect on current inflation compared to LSAP, but LSAP is more effective afterwards.

On December 16, 2008, the FOMC cut the policy rate target to a range from 0 to $1 / 4$ percent and indicated that it expected the target to remain there "for some time". It also stated that the Fed would continue to consider ways of using its balance sheet to further support credit markets and economic activity. As shown in Table 3, both forward guidance and LSAP are expansionary and they together lower the 10-year yield by 7 basis points.

January 28, 2009, is an example where the FOMC statement had explicit easing LSAP language - "...consider ways of using its balance sheet to further support credit markets and economic activity"- but it was perceived by some market participants as disappointing because of its lack of concrete language regarding the possibility and timing of purchases of longer-term Treasuries in the secondary market. As shown in Table 3, my identification procedure finds contractionary forward guidance and LSAP shocks.

The most striking observation in Figure 1 is March 18, 2009. The FOMC decided to purchase "up to an additional $\$ 750$ billion of agency-backed securities", increase "its purchases of agency debt this year by up to $\$ 100$ billion", and purchase "up to $\$ 300$ billion of longer-term Treasury securities over the next six months". In addition, the Committee changed the language about the expected duration of a near-zero policy rate to "for an extended period". Hence there was explicit forward guidance policy announced at the same time as LSAP policy. Figure 10 plots the estimated effects of the forward guidance and LSAP announcements. The LSAP is more powerful in that it increases the one-year-ahead output by 0.71 percent and increases one-year-ahead inflation by 0.39 annualized percentage points.

\subsection{QE II Phase (November 2010 to June 2011)}

It's also interesting that the FOMC's subsequent QE II program, launched on November 3, 2010, has very small easing forward guidance and LSAP surprises. A possible reason 
discussed in the literature, e.g., Krishnamurthy et al. (2011) and Bauer \& Rudebusch (2014), is that expectations of QE II were incrementally formed before official confirmation. The event study on the single QE II official announcement day may underestimate the full effect of the program. Therefore, I follow Krishnamurthy et al. (2011) and include two important pre-announcement QE II news. The first one is on August 10, 2010, when the Fed's announcement to continue QE revised market expectations of exiting. The second one is on September 21, 2010, when the FOMC was "prepared to provide additional accommodation if needed". The August announcement appears to be significant news for the Treasury market, while the September announcement's effects are smaller. As shown in Figure 1, I estimate a significant 1.3 units of easing forward guidance shock and a significant 0.5 unit easing LSAP shock on August 10, while the estimates on September 21 and November 3 are insignificant from zero.

\subsection{Mid-2013 Phase (November 2010 to June 2011)}

August 9, 2011, is the first announcement in which the FOMC gave explicit "calendarbased" forward guidance. The FOMC stated that it expected the current level of the federal funds rate would be appropriate "at least through mid-2013". I estimate that the major driving force of the 10-year Treasury yield drop was due to the information component. The monetary policy shocks are insignificant.

\section{4 "Operation Twist" (September 2011 to August 2012)}

September 21, 2011 is one of the dates when my results are different from Swanson (2021). It corresponds to "Operation Twist". The FOMC announced it would purchase $\$ 400$ billion of Treasury securities of median- and long-term maturities and sell an equal amount of short-term Treasury securities. This program "should put downward pressure on longer-term interest rates and help make broader financial conditions more accommodative". Swanson (2021)'s identification procedure for forward guidance vs. LSAP announcements attributes the effects of this announcement to a tightening forward guidance and an easing LSAP factor. It is surprising for the two types of unconventional monetary polices implied from the same announcement to have different directions. However, my identification estimates this announcement to have both LSAP and forward guidance components in the easing direction. The forward guidance on that day decreased the 10-year Treasury yield by 0.1 basis points, while the LSAP had an effect of 2.4 basis points. 


\subsection{QE III Phase (September 2012 to May 2013)}

On December 12, 2012, the Fed adjusted its forward guidance from the calendarbased language "at least through mid-2015" to forward guidance based on unemployment and expected inflation. The policy statement read: "...this exceptionally low range for the federal funds rate will be appropriate at least as long as the unemployment rate remains above 6-1/2 percent, inflation between one and two years ahead is projected to be no more than a half percentage point above the Committee's 2 percent longer-run goal". This resulted in some concerns from investors that the central bank would have to start tightening policy earlier than the time they anticipated before The Wall Street Journal (2012). Therefore, the medium-term and long-term yields increased.

\subsection{Tapering (June 2013 to October 2014)}

On June 19, 2013, there is little change in the FOMC statement, but the FOMC released economic projections that showed a substantial increase in the FOMC's economic outlook. Given earlier remarks by Chairman Ben Bernanke that the FOMC could begin tapering its asset purchases soon, markets interpreted this as a signal that a tapering was imminent. Moreover, the FOMC statement says, “...14 of 19 FOMC participants indicated that they expect the first increase in the target for the federal funds rate to occur in 2015, and one expected the first increase to incur in 2016". Thus, this episode fits into the "taper tantrum" period, and I have identified a large tightening forward guidance factor and a medium-size tightening LSAP factor. I have estimated that the forward guidance would decrease one-year-ahead output by 0.06 percent and inflation by 0.05 annualized percentage points, and the LSAP would decrease one-year-ahead output by 0.20 percent and inflation by 0.10 annualized percentage points.

On September 18, 2013, the FOMC was widely expected to begin tapering its asset purchases, but it turned out not to do so. The surprise decision by the FOMC not to taper its asset purchases is correctly identified in my estimates: the easing LSAP shock together with easing forward guidance shock resulted in a 3 basis points drop of the 10-year yield. This in turn would raise one-year-ahead real GDP by 0.15 percent and inflation by 0.56 annualized percentage points.

On December 18, 2013, the policy statement said that " $\ldots$ it likely will be appropriate to maintain the current target range for the federal funds rate well past the time that the unemployment rate declines below 6-1/2 percent, especially if projected inflation continues to run below the Committee's 2 percent longer-run goal". Evidence shows the labor market 
had improved, and as a result the FOMC decided to begin tapering their monthly asset purchases. The new language on unemployment was probably added to prevent the market from moving up the date in which they expected the federal funds rate to rise.

The Fed ended its bond purchase program on October 29, 2014. However, in the meantime, the FOMC statement said, "The committee judges that it can be patient in beginning to normalize the stance of monetary policy", and "The committee sees this guidance as consistent with its previous statement". According to the response of the yield curve, the market took this decision as a tightening policy, with a larger size of forward guidance effect.

\subsection{Post QE Phase (December 2014 to December 2015)}

The statement on December 17, 2014, said the Fed would be "patient" before raising rates, adding that rates would stay low for a "considerable time." However, that the market expected a hike in the federal funds rate would be coming after two meetings is possible and had confidence that the economy was on track. ${ }^{15}$ Therefore, the whole yield curve was lifted up.

On March 18, 2015, the FOMC removed from its pledge that it will be "patient" before raising interest rates. The Fed downgraded its projections for the U.S. growth outlook significantly below what the markets had expected. The revised forecast was read by financial markets as a sign that the central bank would take its time in raising borrowing costs for the economy. ${ }^{16}$ My estimation appears to correctly identify this announcement as a substantial easing policy, and it lowers the medium-term yield most.

On September 17, 2015, the FOMC decided not to raise its key interest rate. The Fed issued a statement that was widely regarded as more dovish than expected, and released interest rate projections that were substantially lower than before. The 2-year Treasury yield posted its largest single-day decline since late December 2010. The 10-year Treasury yield dropped 9 basis points in the data, which forward guidance accounted for 1.1 basis points and LSAP for 7.5 basis points. It increased one-year-hence real GDP by 0.29 percent and one-year-hence inflation by 0.28 percentage points.

\footnotetext{
${ }^{15}$ https://www.wsj.com/articles/fed-sticks-to-patient-tack-on-rates-1418843005?mg=prod/accounts-wsj

${ }^{16} \mathrm{https}$ // www.wsj.com/articles/ten-year-u-s-government-bond-yield-falls-to-near-2-before-fed-statement1426686629
} 


\section{Conclusion}

In this paper, I show how to identify and estimate the forward guidance and large-scale asset purchase component of every Fed announcement between 2008 and 2015. Building on earlier work by Gertler \& Karadi (2013), the theoretical model shows that an easing forward guidance announcement lowers Treasury yields at all maturities, with a peak effect at a maturity of about 20 months; in contrast, easing LSAP will increase the shortest-maturity Treasury yields because of the feedback of the interest rate rule and will lower medium-term and long-term yields, with the peak effect on the longest maturities.

I match the responses of the yield curve to a linear combination of the two shocks predicted by the model with the observed change in the yield curve in a high-frequency window around each Federal Reserve announcement. In this way, I estimate a time series for each type of unconventional monetary policy announcement and show that these series correspond closely to narrative elements of the Fed announcements and the financial markets commentary.

With the estimates of the shock series, I study the persistence of the monetary policy shocks on aggregate economy using the structural model. My approach circumvents the limitations of the standard event-study methodology. Among the key announcement dates in the QE I program, I find that, compared to forward guidance, LSAP was more important in influencing output and inflation. 


\section{References}

Ang, A., Piazzesi, M. \& Wei, M. (2006), 'What does the yield curve tell us about GDP growth?', Journal of Econometrics 131(1-2), 359-403.

Arellano, C. \& Ramanarayanan, A. (2012), 'Default and the maturity structure in sovereign bonds', Journal of Political Economy 120(2), 187-232.

Bauer, M. D. \& Rudebusch, G. D. (2014), 'The signaling channel for Federal Reserve bond purchases', International Journal of Central Banking .

Bauer, M. \& Swanson, E. (2020), 'The Fed's response to economic news explains the "Fed information effect"', NBER Working Paper.

Baumeistera, C. \& Benatib, L. (2013), 'Unconventional monetary policy and the great recession: Estimating the macroeconomic effects of a spread compression at the zero lower bound', International Journal of Central Banking .

Bhattarai, S., Eggertsson, G. B. \& Gafarov, B. (2015), Time consistency and the duration of government debt: A signalling theory of quantitative easing, Technical report, National Bureau of Economic Research.

Bundick, B. \& Smith, A. L. (2020), 'The dynamic effects of forward guidance shocks', Review of Economics and Statistics 102(5), 946-965.

Calvo, G. A. (1983), 'Staggered prices in a utility-maximizing framework', Journal of Monetary Economics 12(3), 383-398.

Campbell, J. R., Evans, C. L., Fisher, J. D. \& Justiniano, A. (2012), 'Macroeconomic effects of Federal Reserve forward guidance', Brookings Papers on Economic Activity 2012(1), 180 .

Chen, H., Cúrdia, V. \& Ferrero, A. (2012), 'The macroeconomic effects of large-scale asset purchase programmes', The Economic Journal 122(564), F289-F315.

Christiano, L. J., Eichenbaum, M. \& Evans, C. L. (2005), 'Nominal rigidities and the dynamic effects of a shock to monetary policy', Journal of Political Economy 113(1), 1-45.

Chung, H., Laforte, J.-P., Reifschneider, D. \& Williams, J. C. (2012), 'Have we underestimated the likelihood and severity of zero lower bound events?', Journal of Money, Credit and Banking 44(s1), 47-82. 
Cieslak, A. \& Schrimpf, A. (2019), 'Non-monetary news in central bank communication', Journal of International Economics 118, 293-315.

Coibion, O., Gorodnichenko, Y. \& Wieland, J. (2012), 'The optimal inflation rate in New Keynesian models: should central banks raise their inflation targets in light of the zero lower bound?', The Review of Economic Studies p. rds013.

Del Negro, M., Giannoni, M. P. \& Patterson, C. (2015), 'The forward guidance puzzle', FRB of New York Staff Report (574).

Eggertsson, G. B. \& Woodford, M. (2003), 'The zero bound on interest rates and optimal monetary policy', Brookings Papers on Economic Activity 2003(1), 139-211.

Gagnon, J., Raskin, M., Remache, J. \& Sack, B. (2011), 'Large-scale asset purchases by the Federal Reserve: Did they work?', Federal Reserve Bank of New York Economic Policy Review p. 41.

Gertler, M. \& Karadi, P. (2011), 'A model of unconventional monetary policy', Journal of Monetary Economics 58(1), 17-34.

Gertler, M. \& Karadi, P. (2013), 'QE 1 vs. 2 vs. 3...: A framework for analyzing largescale asset purchases as a monetary policy tool', International Journal of Central Banking 9(1), 5-53.

Gertler, M. \& Karadi, P. (2015), 'Monetary policy surprises, credit costs, and economic activity', American Economic Journal: Macroeconomics 7(1), 44-76.

Gilchrist, S. \& Zakrajšek, E. (2013), 'The impact of the Federal Reserve's Large-scale asset purchase programs on corporate credit risk', Journal of Money, Credit and Banking 45(s2), 29-57.

Guerrieri, L. \& Iacoviello, M. (2015), 'OccBin: A toolkit for solving dynamic models with occasionally binding constraints easily', Journal of Monetary Economics 70, 22-38.

Gürkaynak, R. S., Sack, B. \& Swansonc, E. T. (2005), 'Do actions speak louder than words? the response of asset prices to monetary policy actions and statements', International Journal of Central Banking .

Gürkaynak, R. S., Sack, B. \& Wright, J. H. (2007), 'The US Treasury yield curve: 1961 to the present', Journal of Monetary Economics 54(8), 2291-2304. 
Gürkaynak, R. S., Sack, B. \& Wright, J. H. (2010), 'The yield curve and inflation compensation', American Economic Journal: Macroeconomics pp. 70-92.

Jarociński, M. \& Karadi, P. (2019), 'Deconstructing monetary policy surprises: the role of information shocks', American Economic Journal: Macroeconomics forthcoming.

Jordà, Ò. (2005), 'Estimation and inference of impulse responses by local projections', American Economic Review 95(1), 161-182.

Keen, B. D., Richter, A. W. \& Throckmorton, N. A. (2016), 'Forward guidance and the state of the economy', Working Paper.

Krippner, L. (2016), 'Documentation for measures of monetary policy', Reserve Bank of New Zealand Working Paper .

Krishnamurthy, A., Vissing-Jorgensen, A., Gilchrist, S. \& Philippon, T. (2011), 'The effects of quantitative easing on interest rates: Channels and implications for policy [with comments and discussion]', Brookings Papers on Economic Activity pp. 215-287.

Laséen, S. \& Svensson, L. E. (2011), 'Anticipated alternative policy rate paths in policy simulations', International Journal of Central Banking 7(3), 1-35.

Miranda-Agrippino, S. \& Ricco, G. (2018), 'The transmission of monetary policy shocks', Working Paper .

Nakamura, E. \& Steinsson, J. (2018), 'High-frequency identification of monetary nonneutrality: the information effect', The Quarterly Journal of Economics 133(3), 12831330.

Nelson, C. R. \& Siegel, A. F. (1987), 'Parsimonious modeling of yield curves', The Journal of Business 60(4), 473-489.

Ray, W. (2019), 'Monetary policy and the limits to arbitrage: Insights from a New Keynesian preferred habitat model', Working Paper .

Romer, C. D. \& Romer, D. H. (2004), 'A new measure of monetary shocks: Derivation and implications', American Economic Review 94(4), 1055-1084.

Sims, E. \& Wu, J. C. (2021), 'Evaluating central banks' tool kit: Past, present, and future', Journal of Monetary Economics 118, 135-160. 
Swanson, E. (2015), 'A macroeconomic model of equities and real, nominal, and defaultable debt', Unpublished Manuscript, University of California, Irvine .

Swanson, E. T. (2021), 'Measuring the effects of federal reserve forward guidance and asset purchases on financial markets', Journal of Monetary Economics 118, 32-53.

Swanson, E. T. \& Williams, J. C. (2014), 'Measuring the effect of the zero lower bound on medium-and longer-term interest rates', The American Economic Review 104(10), 31543185 .

The Wall Street Journal (2008a), 'Data expected to confirm deflation trend'. Mark Gongloff, November 26, 2008.

The Wall Street Journal (2008b), 'Fear recedes in the debt markets'. Michael Aneiro, Novermber 26, 2008, Credit Market.

The Wall Street Journal (2012), 'Treasurys fall after Fed decision'. Cynthia Lin, December $12,2012$.

Woodford, M. (2001), 'Fiscal requirements for price stability', Journal of Money, Credit, and Banking 33(3), 669.

Wright, J. H. (2012), 'What does monetary policy do to long-term interest rates at the zero lower bound?', The Economic Journal 122(564).

Wu, J. C. \& Xia, F. D. (2016), 'Measuring the macroeconomic impact of monetary policy at the zero lower bound', Journal of Money, Credit and Banking 48(2-3), 253-291.

Wu, J. C. \& Zhang, J. (2019), 'A shadow rate new keynesian model', Journal of Economic Dynamics and Control 107, 103728.

Wu, M. T. (2014), Unconventional monetary policy and long-term interest rates, number 14-189, International Monetary Fund.

Zhang, X. (2018), 'Disentangling the information effects in the Federal Reserve's monetary policy announcements', Working Paper . 
Table 1: Other Equations

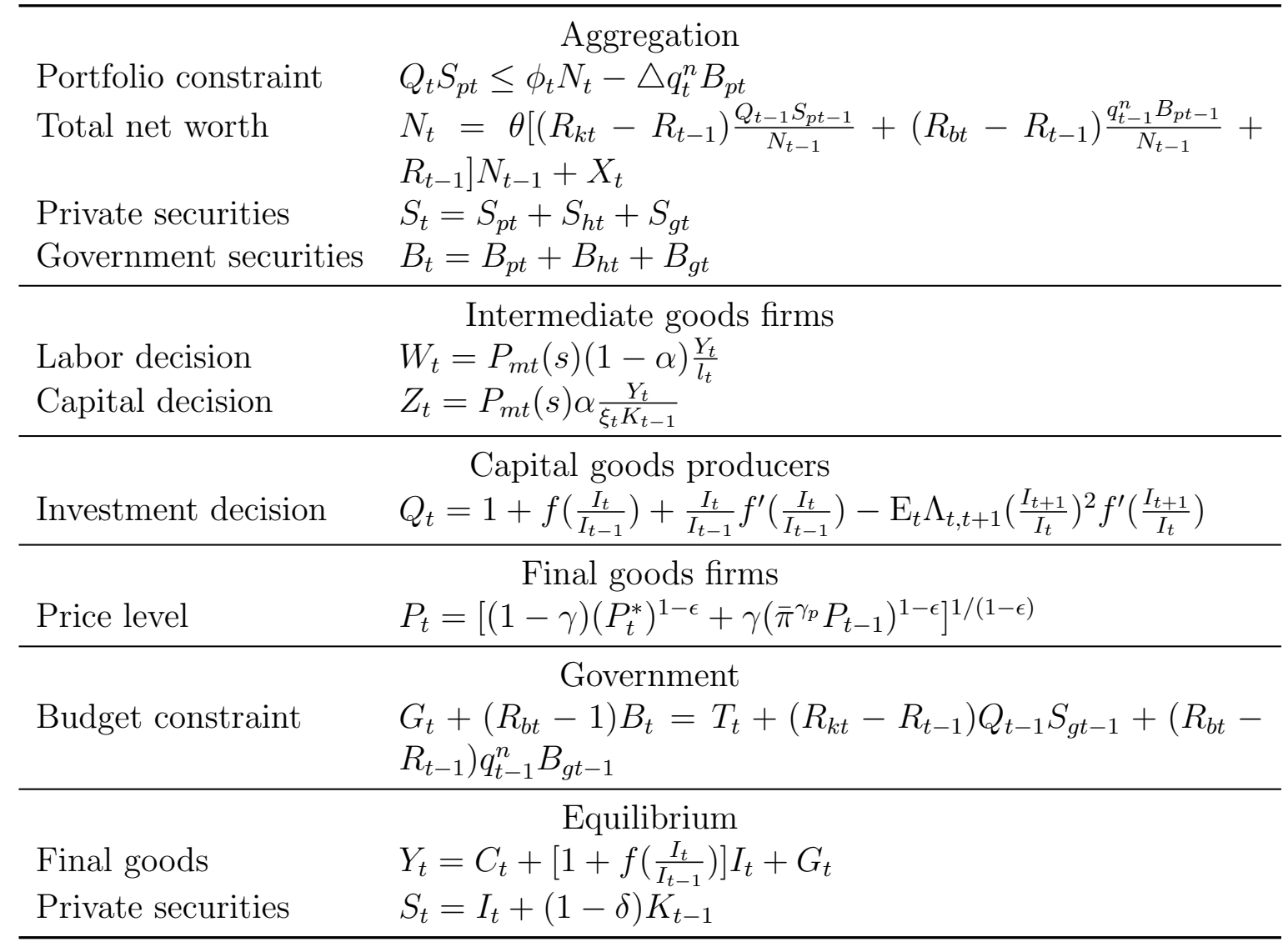


Table 2: Parameter Values

\begin{tabular}{|c|c|c|c|c|c|}
\hline & symbol & value & meaning & value in GK & meaning \\
\hline \multirow{18}{*}{ (A) } & \multicolumn{5}{|c|}{ Parameters in common with GK $(2011,2013)$} \\
\hline & $\beta$ & 0.995 & ss. annual real interest rate $=2$ percent & & \\
\hline & $h$ & 0.615 & habit persistent & & \\
\hline & $\delta$ & 0.025 & depreciation rate & & \\
\hline & $\alpha$ & 0.33 & capital share in production function & & \\
\hline & $\gamma$ & 0.779 & Calvo price-setting, resets every 13.6 months & & \\
\hline & $\gamma^{P}$ & 0 & inflation indexation & & \\
\hline & $\phi_{s s}$ & 4 & ss. leverage ratio & 4,6 & \\
\hline & $G_{s s} / Y$ & 0.2 & ss. government spending-GDP ratio & & \\
\hline & $\mathrm{E}_{s s}$ & $1 / 3$ & ss. labor supply & & \\
\hline & $\eta_{i}$ & 5.17 & quadratic investment cost parameter & & \\
\hline & $\phi_{y}$ & 0.125 & response of monetary policy to output gap & & \\
\hline & $\lambda$ & 0.381 & fraction of capital that can be diverted & $0.381,0.345$ & \\
\hline & $\bar{K}^{h} / K$ & 0.5 & prop. of ss. capital holdings of the hh. & & \\
\hline & $\bar{B}^{h} / B$ & 0.75 & prop. of ss. Treasury holdings of the hh. & & \\
\hline & $B / Y$ & 0.45 & ss. Treasury supply & & \\
\hline & $\rho_{1 b}$ & 1.5 & $\mathrm{AR}(2)$ process governing LSAP & & \\
\hline & $\rho_{2 b}$ & -.55 & $\mathrm{AR}(2)$ process governing LSAP & & \\
\hline (B) & \multicolumn{5}{|c|}{ Parameters changed from GK in order to more accurately match the yield curve } \\
\hline & $\bar{\pi}$ & 0.006 & annual inflation target $=2.4$ percent & 0 & \\
\hline & $\underline{\imath}$ & 0.25 & lower-bound of interest rate, annu. pp & 0 & \\
\hline & $R_{k, s s}-R_{s s}$ & 172 & ss. excess return on capital, annu. bp. & 100 & \\
\hline & $R_{b, s s}-R_{s s}$ & 103 & ss. excess return on bond, annu. bp. & 50 & \\
\hline & $\kappa_{s}$ & 4 & elasticity for hh. holdings of capital & 1 & \\
\hline & $\kappa_{b}$ & 2 & elasticity for hh. holdings of bonds & 1 & \\
\hline \multirow[t]{4}{*}{$(\mathrm{C})$} & \multicolumn{5}{|c|}{$\begin{array}{l}\text { Parameters changed from GK in order to be more consistent with the } \\
\text { consensus from other studies }\end{array}$} \\
\hline & $\varphi$ & $1 / 2$ & Frisch elasticity of labor supply $=1 / \varphi=2$ & 0.276 & 3.6 \\
\hline & $\epsilon$ & 6 & price markup $20 \%$ & 4.167 & $31.58 \%$ \\
\hline & $\phi_{\pi}$ & 2.5 & response of monetary policy to inflation & 1.5 & \\
\hline (D) & \multicolumn{5}{|c|}{ Parameters not in GK } \\
\hline & $\rho_{z}$ & 0.65 & $\mathrm{AR}(1)$ process governing forward guidance & & \\
\hline & $\vartheta$ & 0.98 & Macauley duration 30 quarters & & \\
\hline & $\phi_{2}$ & 0.979 & average yields pre ZLB & & \\
\hline & $\sigma_{n}$ & depends on maturity $n$ & average yields during ZLB & & \\
\hline
\end{tabular}


Table 3: Effect of Monetary Shocks on 10-Year Treasury Yield, Expected Output Growth and Inflation

\begin{tabular}{|c|c|c|c|c|c|c|c|c|}
\hline Date & FG units & LSAP units & $\triangle i_{10 t}^{f g}$ & $\triangle i_{10 t}^{l s a p}$ & $\triangle \mathrm{GDP}_{t+1 y}^{f g}$ & $\triangle \mathrm{GDP}_{t+1 y}^{l s a p}$ & $\triangle \mathrm{infl}_{t+1 y}^{f g}$ & $\triangle \operatorname{infl}_{t+1 y}^{l s a p}$ \\
\hline \multicolumn{9}{|c|}{ QE I phase (November 2008 to March 2010) } \\
\hline Nov-25-2008 & -0.8 & -0.2 & -0.4 & -2.1 & 0.02 & 0.08 & 0.02 & 0.04 \\
\hline Dec-1-2008 & $0.3^{\dagger}$ & $0.1^{\dagger}$ & 0.1 & 1.1 & -0.01 & -0.04 & -0.01 & -0.02 \\
\hline Dec-16-2008 & -2.1 & -0.6 & -1.0 & -6.0 & 0.06 & 0.22 & 0.05 & 0.12 \\
\hline Jan-28-2009 & 2.7 & 0.6 & 1.2 & 6.1 & -0.07 & -0.21 & -0.06 & -0.11 \\
\hline Mar-18-2009 & -5.0 & -2.1 & -2.2 & -20.5 & 0.13 & 0.71 & 0.11 & 0.39 \\
\hline Apr-29-2009 & $1.3^{\dagger}$ & $0.2^{\dagger}$ & 0.6 & 2.5 & -0.03 & -0.08 & -0.03 & -0.04 \\
\hline Jun-24-2009 & 4.1 & 0.9 & 1.8 & 9.2 & -0.11 & -0.32 & -0.09 & -0.17 \\
\hline Aug-12-2009 & 1.9 & 0.5 & 0.8 & 4.7 & -0.05 & -0.16 & -0.04 & -0.08 \\
\hline Sep-23-2009 & -2.9 & -0.7 & -1.3 & -7.4 & 0.08 & 0.27 & 0.06 & 0.15 \\
\hline Nov-4-2009 & 1.1 & 0.3 & 0.5 & 3.1 & -0.03 & -0.10 & -0.02 & -0.05 \\
\hline Dec-16-2009 & 0.8 & 0.2 & 0.3 & 2.4 & -0.02 & -0.08 & -0.02 & -0.04 \\
\hline Jan-27-2010 & $0.6^{\dagger}$ & $0.0^{\dagger}$ & 0.3 & 0.1 & -0.02 & 0.00 & -0.01 & 0.00 \\
\hline Mar-16-2010 & $-0.2^{\dagger}$ & $0.1^{\dagger}$ & -0.1 & 1.6 & 0.00 & -0.03 & 0.00 & -0.02 \\
\hline \multirow[t]{2}{*}{ Sum } & & & -0.2 & -10.6 & 0.00 & 0.41 & 0.00 & 0.24 \\
\hline & & \multicolumn{7}{|c|}{ Pre-QE II phase (April 2010 to October 2010) } \\
\hline Apr-28-2010 & $0.2^{\dagger}$ & $0.1^{\dagger}$ & 0.1 & 0.7 & -0.01 & -0.02 & -0.01 & -0.01 \\
\hline Jun-23-2010 & 0.9 & 0.3 & 0.4 & 2.7 & -0.03 & -0.09 & -0.02 & -0.05 \\
\hline Aug-10-2010 & -1.3 & -0.5 & -0.6 & -5.4 & 0.04 & 0.20 & 0.03 & 0.11 \\
\hline Sep-21-2010 & $0.1^{\dagger}$ & $0.1^{\dagger}$ & 0.0 & 0.7 & 0.00 & -0.02 & 0.00 & -0.01 \\
\hline Nov-3-2010 & $0.7^{\dagger}$ & $0.3^{\dagger}$ & 0.3 & 2.6 & -0.02 & -0.09 & -0.02 & -0.04 \\
\hline Sum & & & -0.2 & -2.7 & 0.01 & 0.11 & 0.01 & 0.06 \\
\hline \multicolumn{9}{|c|}{ QE II phase (November 2010 to June 2011) } \\
\hline Dec-14-2010 & $0.2^{\dagger}$ & $0.1^{\dagger}$ & 0.1 & 0.5 & -0.01 & -0.01 & 0.00 & -0.01 \\
\hline Jan-26-2011 & -0.4 & 0.0 & -0.2 & -0.3 & 0.01 & 0.01 & 0.01 & 0.01 \\
\hline Mar-15-2011 & 0.9 & 0.2 & 0.4 & 1.6 & -0.02 & -0.05 & -0.02 & -0.03 \\
\hline Apr-27-2011 & -0.9 & -0.1 & -0.4 & -1.4 & 0.03 & 0.05 & 0.02 & 0.03 \\
\hline Jun-22-2011 & 1.8 & 0.5 & 0.8 & 5.3 & -0.05 & -0.18 & -0.04 & -0.10 \\
\hline Sum & & & 0.6 & 5.3 & -0.04 & -0.17 & -0.03 & -0.09 \\
\hline
\end{tabular}




\begin{tabular}{|c|c|c|c|c|c|c|c|c|}
\hline Date & FG units & LSAP units & $\triangle i_{10 t}^{f g}$ & $\triangle i_{10 t}^{l s a p}$ & $\triangle \mathrm{GDP}_{t+1 y}^{f g}$ & $\triangle \mathrm{GDP}_{t+1 y}^{l s a p}$ & $\triangle \mathrm{infl}_{t+1 y}^{f g}$ & $\triangle \operatorname{infl}_{t+1 y}^{l s a p}$ \\
\hline \multicolumn{9}{|c|}{ Mid-2013 phase (August 2011) } \\
\hline Aug-9-2011 & $-0.1^{\dagger}$ & $0.1^{\dagger}$ & -0.1 & 0.5 & 0.00 & -0.02 & 0.00 & -0.01 \\
\hline \multicolumn{9}{|c|}{ "Operation Twist" (September 2011 to August 2012) } \\
\hline Sep-21-2011 & $-0.3^{\dagger}$ & -0.2 & -0.1 & -2.4 & 0.01 & 0.09 & 0.01 & 0.05 \\
\hline Nov-2-2011 & -0.7 & $-0.1^{\dagger}$ & -0.3 & -1.3 & 0.02 & 0.05 & 0.01 & 0.03 \\
\hline Dec-13-2011 & -0.2 & -0.1 & -0.1 & -1.1 & 0.00 & 0.04 & 0.00 & 0.02 \\
\hline Jan-25-2012 & -1.3 & -0.4 & -0.6 & -4.0 & 0.04 & 0.15 & 0.03 & 0.08 \\
\hline Mar-13-2012 & 0.9 & 0.2 & 0.4 & 2.5 & -0.02 & -0.08 & -0.02 & -0.04 \\
\hline Apr-25-2012 & -0.1 & $0.0^{\dagger}$ & 0.0 & -0.3 & 0.00 & 0.01 & 0.00 & 0.01 \\
\hline Jun-30-2012 & 0.6 & $0.0^{\dagger}$ & 0.3 & 0.3 & -0.02 & -0.01 & -0.01 & 0.00 \\
\hline Aug-1-2012 & 1.4 & 0.3 & 0.6 & 3.4 & -0.04 & -0.11 & -0.03 & -0.06 \\
\hline Sum & & & 0.3 & -1.6 & -0.02 & 0.08 & -0.02 & 0.05 \\
\hline \multicolumn{9}{|c|}{ QE III phase (September 2012 to May 2013) } \\
\hline Sep-13-2012 & 1.7 & 0.5 & 0.7 & 4.5 & -0.05 & -0.15 & -0.04 & -0.08 \\
\hline Oct-14-2012 & -1.4 & -0.5 & -0.6 & -4.8 & 0.04 & 0.18 & 0.03 & 0.10 \\
\hline Dec-12-2012 & 0.5 & 0.2 & 0.2 & 1.5 & -0.01 & -0.05 & -0.01 & -0.03 \\
\hline Jan-30-2013 & -0.4 & $-0.1^{\dagger}$ & -0.2 & -0.8 & 0.01 & 0.03 & 0.01 & 0.02 \\
\hline Mar-20-2013 & -0.6 & -0.2 & -0.3 & -2.2 & 0.02 & 0.08 & 0.01 & 0.04 \\
\hline May-1-2013 & 0.3 & $0.0^{\dagger}$ & 0.1 & 0.5 & -0.01 & -0.01 & -0.01 & -0.01 \\
\hline Sum & & & 0.0 & -1.0 & 0.00 & 0.05 & 0.00 & 0.03 \\
\hline \multicolumn{9}{|c|}{ Tapering (June 2013 to October 2014) } \\
\hline Jun-19-2013 & 2.3 & 0.6 & 1.0 & 5.7 & -0.06 & -0.20 & -0.05 & -0.10 \\
\hline Jul-31-2013 & -0.3 & 0.0 & -0.1 & -0.5 & 0.01 & 0.02 & 0.01 & 0.01 \\
\hline Sep-18-2013 & -3.1 & -1.0 & -1.4 & -10.0 & 0.08 & 0.36 & 0.07 & 0.20 \\
\hline Oct-30-2013 & 0.7 & 0.2 & 0.3 & 2.1 & -0.02 & -0.07 & -0.02 & -0.04 \\
\hline Dec-18-2013 & -0.3 & -0.1 & -0.1 & -0.8 & 0.01 & 0.03 & 0.01 & 0.02 \\
\hline Jan-29-2014 & -0.8 & -0.3 & -0.3 & -3.4 & 0.02 & 0.13 & 0.02 & 0.07 \\
\hline Mar-19-2014 & 2.3 & 0.5 & 1.0 & 4.9 & -0.06 & -0.17 & -0.05 & -0.09 \\
\hline Apr-30-2014 & -0.5 & -0.1 & -0.2 & -0.9 & 0.01 & 0.03 & 0.01 & 0.02 \\
\hline Jun-18-2014 & $-0.1^{\dagger}$ & $0.0^{\dagger}$ & -0.1 & 0.0 & 0.00 & 0.00 & 0.00 & 0.00 \\
\hline Jul-30-2014 & -1.2 & -0.3 & -0.5 & -2.8 & 0.03 & 0.10 & 0.03 & 0.06 \\
\hline
\end{tabular}




\begin{tabular}{|c|c|c|c|c|c|c|c|c|}
\hline Date & FG units & LSAP units & $\triangle i_{10 t}^{f g}$ & $\triangle i_{10 t}^{l s a p}$ & $\triangle \mathrm{GDP}_{t+1 y}^{f g}$ & $\triangle \mathrm{GDP}_{t+1 y}^{l s a p}$ & $\triangle \operatorname{infl}_{t+1 y}^{f g}$ & $\triangle$ infllsap $_{t+1 y}^{\text {sap }}$ \\
\hline Sep-17-2014 & 1.0 & $0.2^{\dagger}$ & 0.4 & 2.0 & -0.03 & -0.06 & -0.02 & -0.03 \\
\hline Oct-29-2014 & 1.2 & 0.2 & 0.5 & 2.5 & -0.03 & -0.08 & -0.03 & -0.04 \\
\hline Sum & & & 0.6 & -3.3 & -0.04 & 0.15 & -0.03 & 0.09 \\
\hline \multicolumn{9}{|c|}{ Post QE } \\
\hline Dec-17-2014 & -1.8 & -0.4 & -0.8 & -3.8 & 0.05 & 0.14 & 0.04 & 0.08 \\
\hline
\end{tabular}

NOTES: Columns 2 and 3 are the estimated units of each policy. Columns 4 and 5 are the contribution of forward guidance and LSAP to the monetary policy component of 10-year Treasury yield change. Columns 6 to 9 show the effects of forward guidance and LSAP on one-year-ahead output and the annualized inflation rate (in percentage points). $\dagger$ indicates the estimate is insignificant at the $10 \%$ level. The sum of each event day is calculated using only the significant estimates. The categorization of QE I, QE II, "Operation Twist" and QE III comes from $\mathrm{Wu}(2014)$. 
Figure 1: Estimated Forward Guidance and LSAP Shocks Over Time

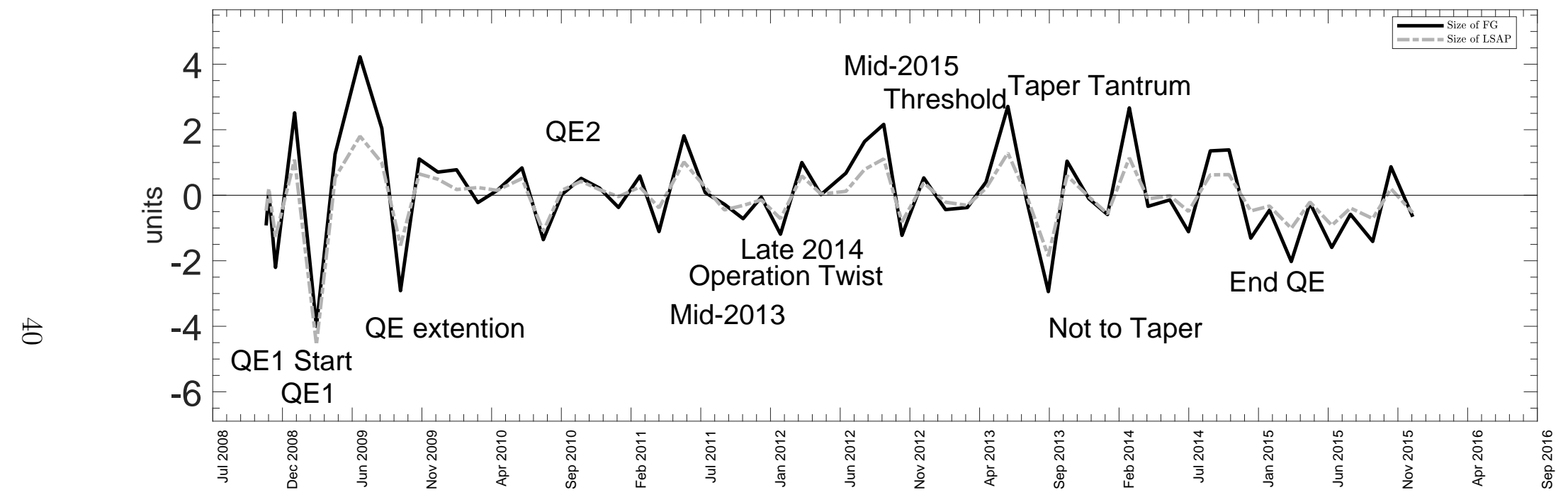

Notes: This figure plots the estimated sizes of forward guidance and LSAP shocks between November 2008 and December 2015. One unit of easing forward guidance shock (negative number) is defined to lower the nominal shadow rate by 25 basis points on impact. One unit of easing LSAP shock (negative number) is defined to lower the 10-year Treasury yield by 5 basis points on impact. Notable announcements are labeled in the figure for reference. See text for details. 
Figure 2: No-Policy-Response Crisis, Impulse Responses to Capital Quality Shock
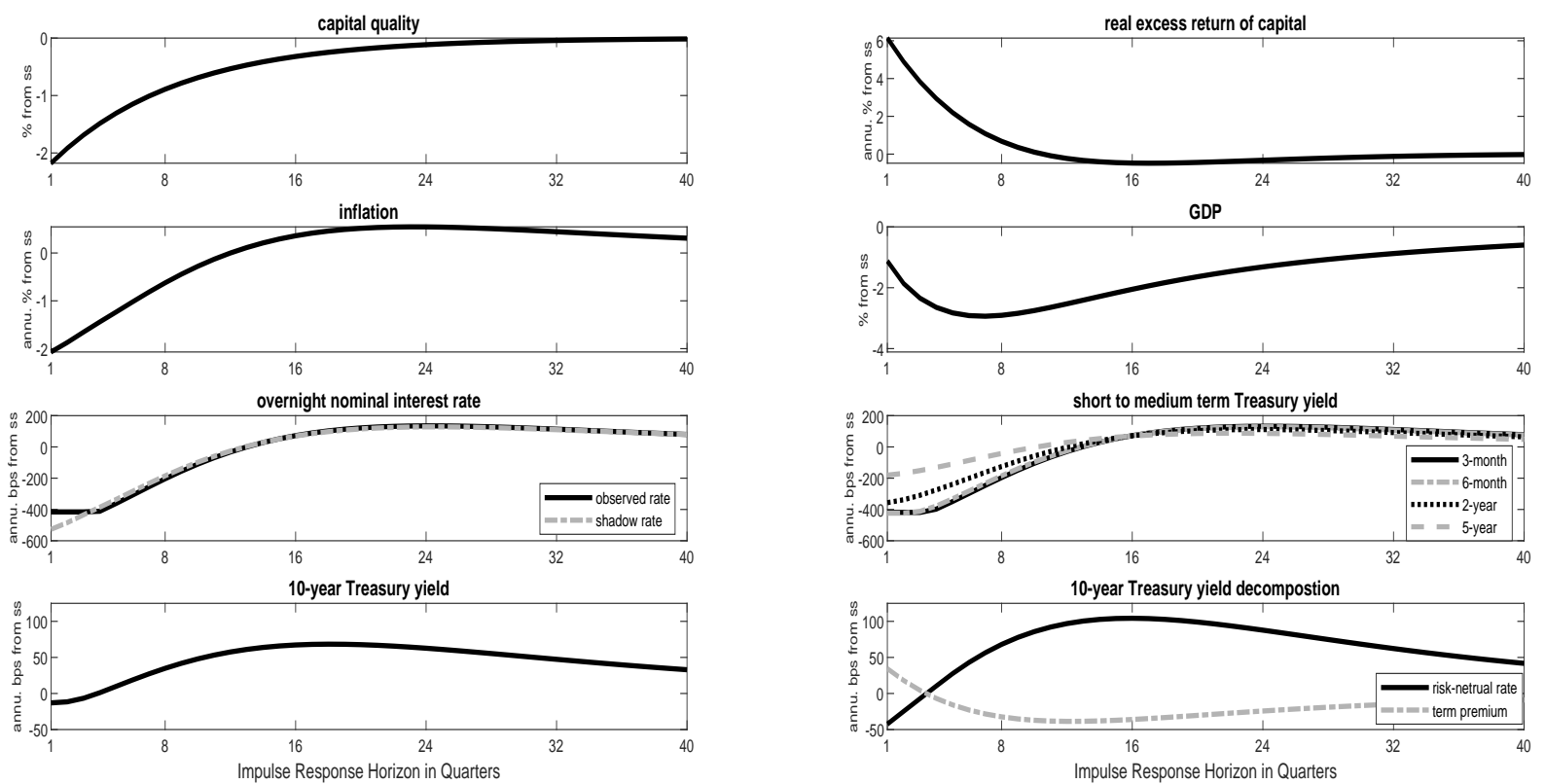

Notes: This figure shows the dynamic responses of the excess return of capital; inflation; output; the overnight, 3-month, 6-month, 2-year, 5-year and 10-year yields; 10-year risk neutral rate; and term premium to a negative capital quality shock. 
Figure 3: Differences of the Impulse Responses with FG Policy from a No-Policy-Response Crisis
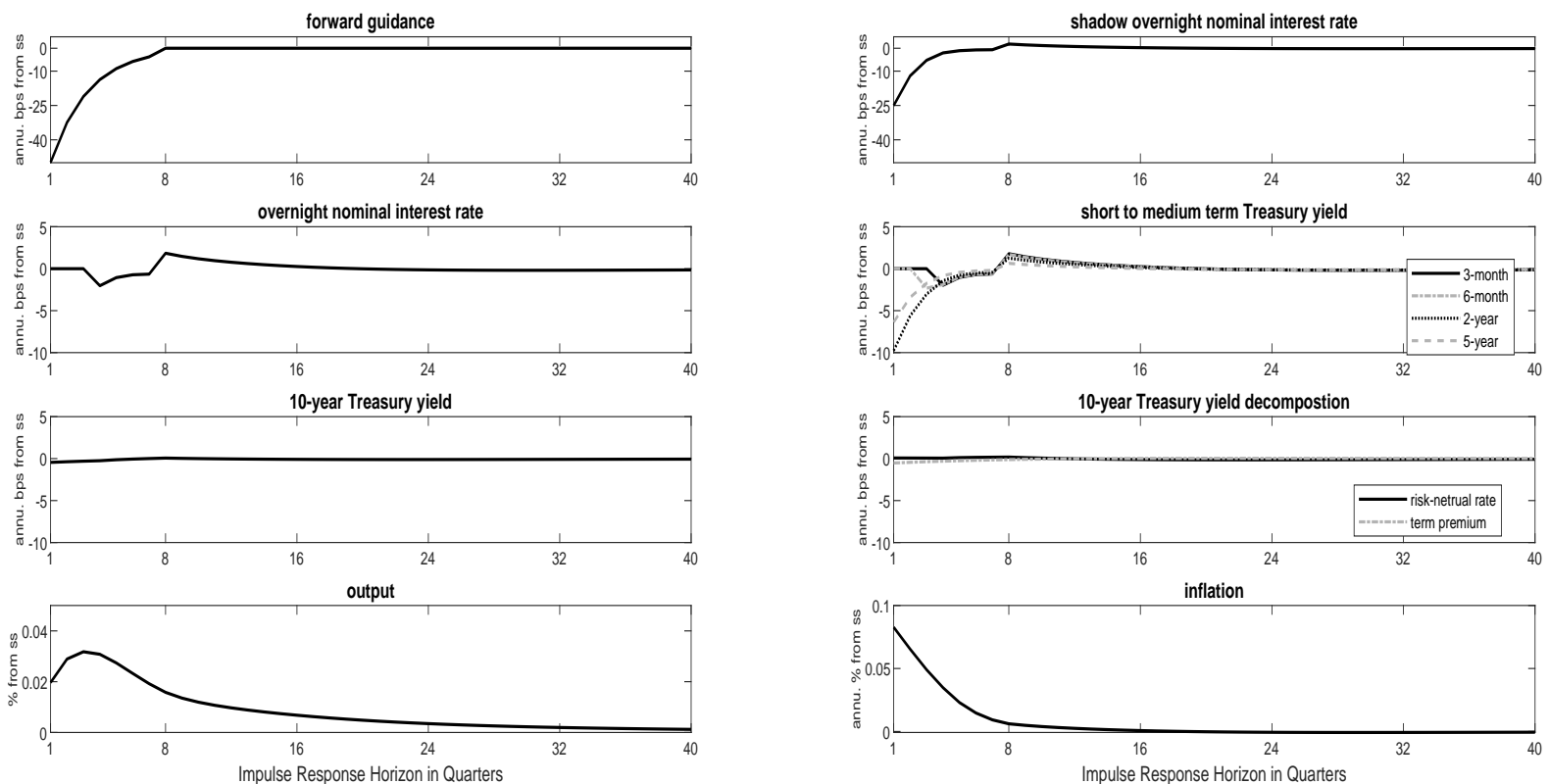

Notes: This figure shows the changes in the responses of the excess return of capital; inflation; output; the overnight, 3-month, 6-month, 2-year, 5-year and 10-year yields; 10-year risk neutral rate; and term premium when a one-unit of forward guidance policy is introduced at the beginning of the crisis. 
Figure 4: Differences of the Impulse Responses with LSAP Policy from a No-Policy-Response Crisis
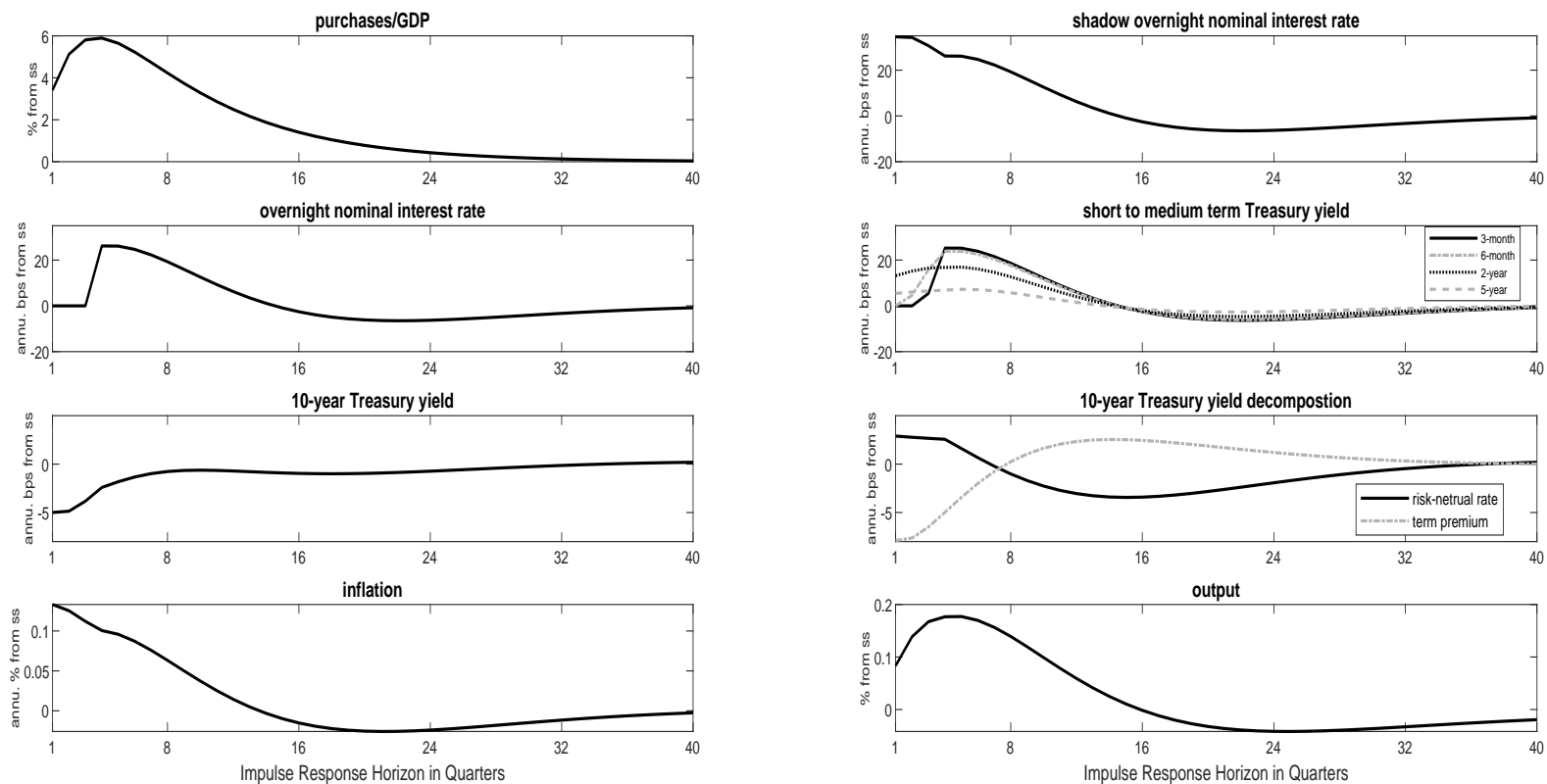

Notes: This figure shows the changes in the responses of the excess return of capital; inflation; output; the overnight, 3-month, 6-month, 2-year, 5-year and 10-year yields; 10-year risk neutral rate; and term premium when a one-unit of LSAP policy is introduced at the beginning of the crisis. 
Figure 5: Difference between Fitted Yield Curves from a No-Policy-Response Crisis (Easing Policy)

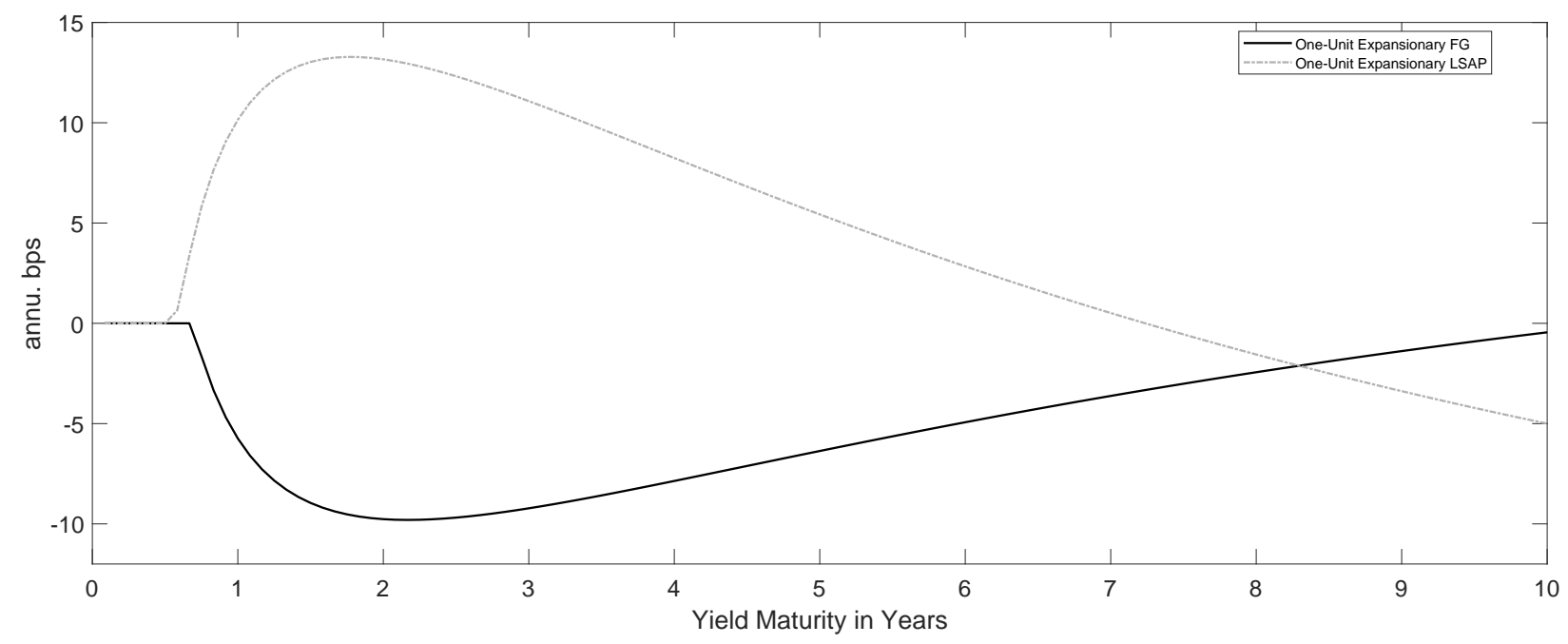

Notes: This figure shows the impact on the yield curve when a one-unit of forward guidance policy (solid line) and a one-unit of LSAP policy (dashed line) is introduced at the beginning of the crisis. 
Figure 6: Decomposition of 5-Year Treasury Yield into Info, Non-info, FG and LSAP
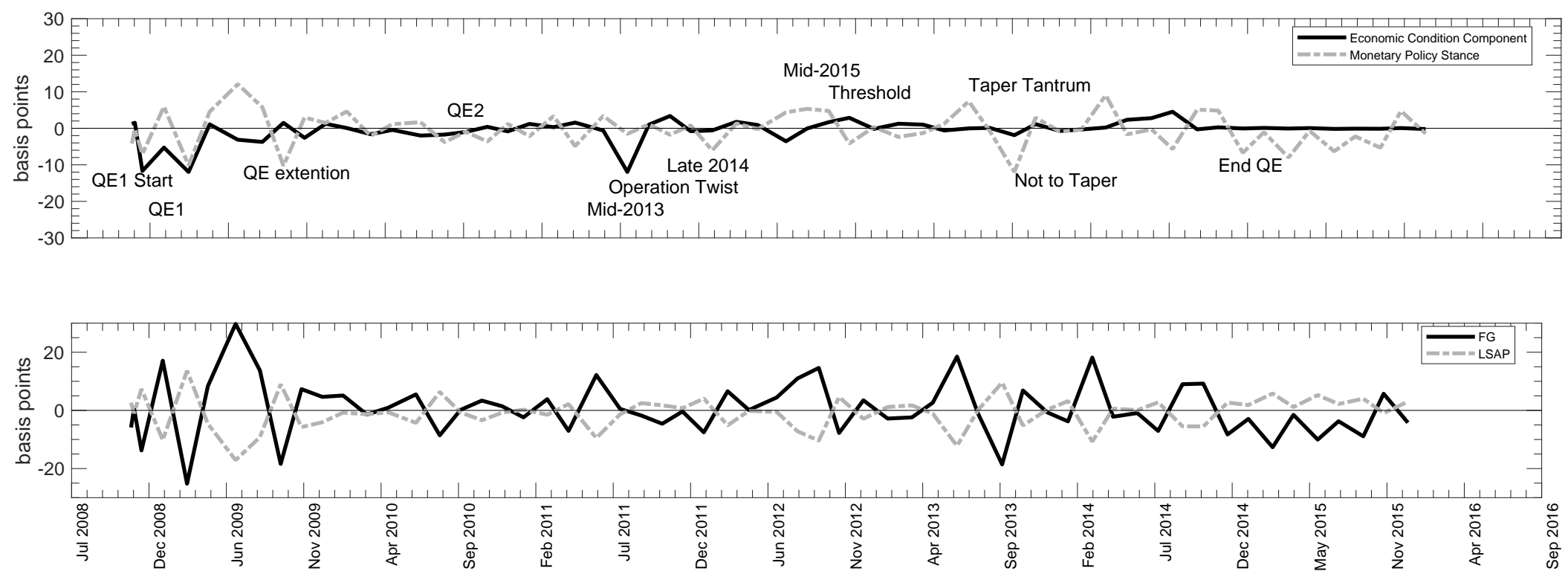

Notes: This figure plots the information and monetary policy component (upper panel) and the contribution from forward guidance and LSAP policies (lower panel) for all the event dates. Notable announcements are labeled in the figure for reference. See text for details. 
Figure 7: Decomposition of 10-Year Treasury Yield into Info, Non-info, FG and LSAP
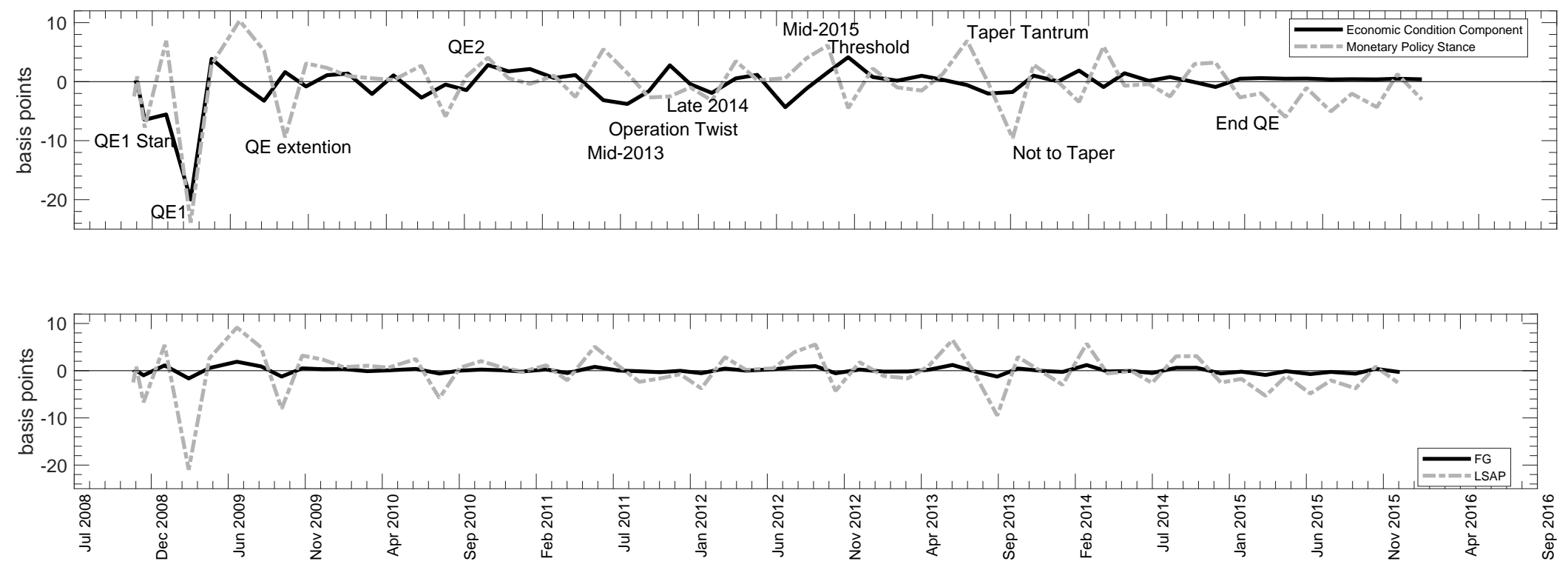

Notes: This figure plots the information and monetary policy component (upper panel) and the contribution from forward guidance and LSAP policies (lower panel) for all the event dates. Notable announcements are labeled in the figure for reference. See text for details. 
Figure 8: Effects on the Fitted Yield Curves, LSAP Using Swanson (2021)'s Definition

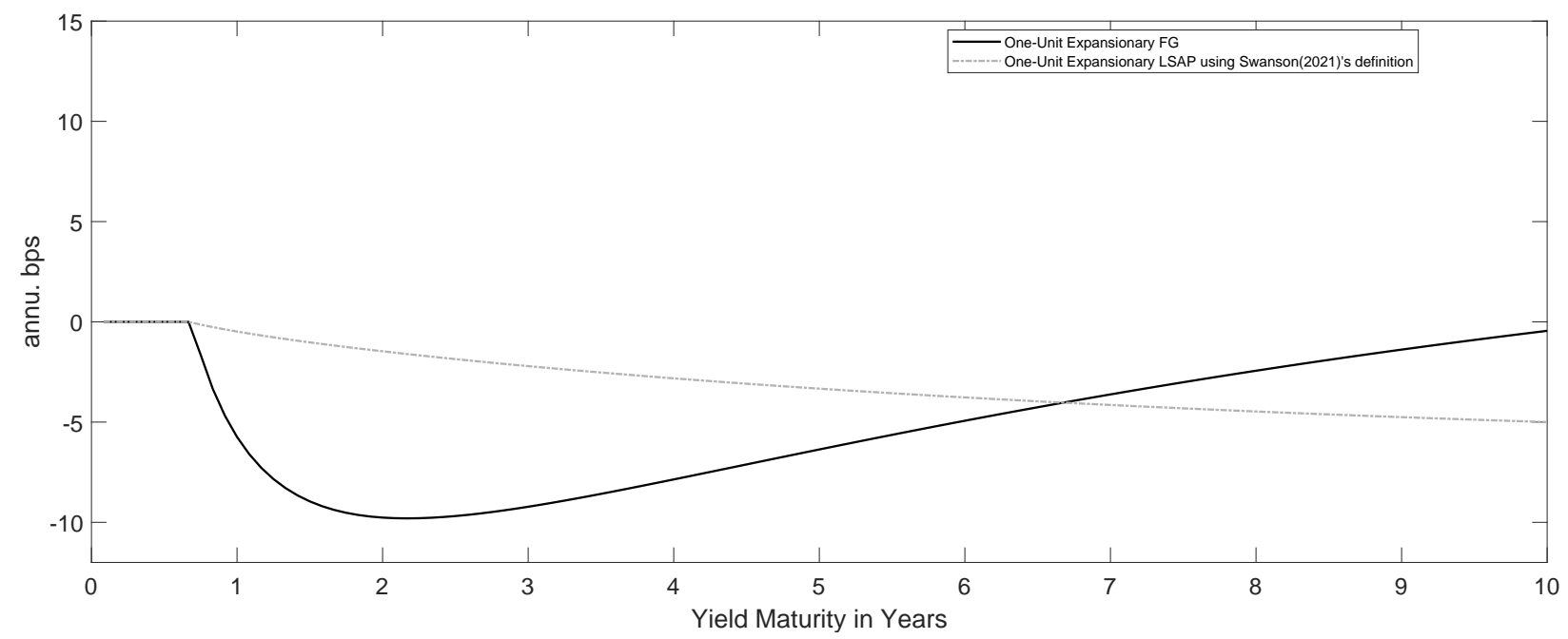

Notes: This figure shows the the impact on the yield curve from a one-unit of forward guidance policy (solid line) and a one-unit redefined LSAP policy (dashed line). The forward guidance shock is the same as in Figure 5. The LSAP shock is redefined to be a combination of the structural shocks such that the 10 -year rate drops by 5 basis points while the shadow rate is unchanged, a definition similar to the LSAP shock in Swanson (2021). 
Figure 9: Impulse Response on November 25, 2008
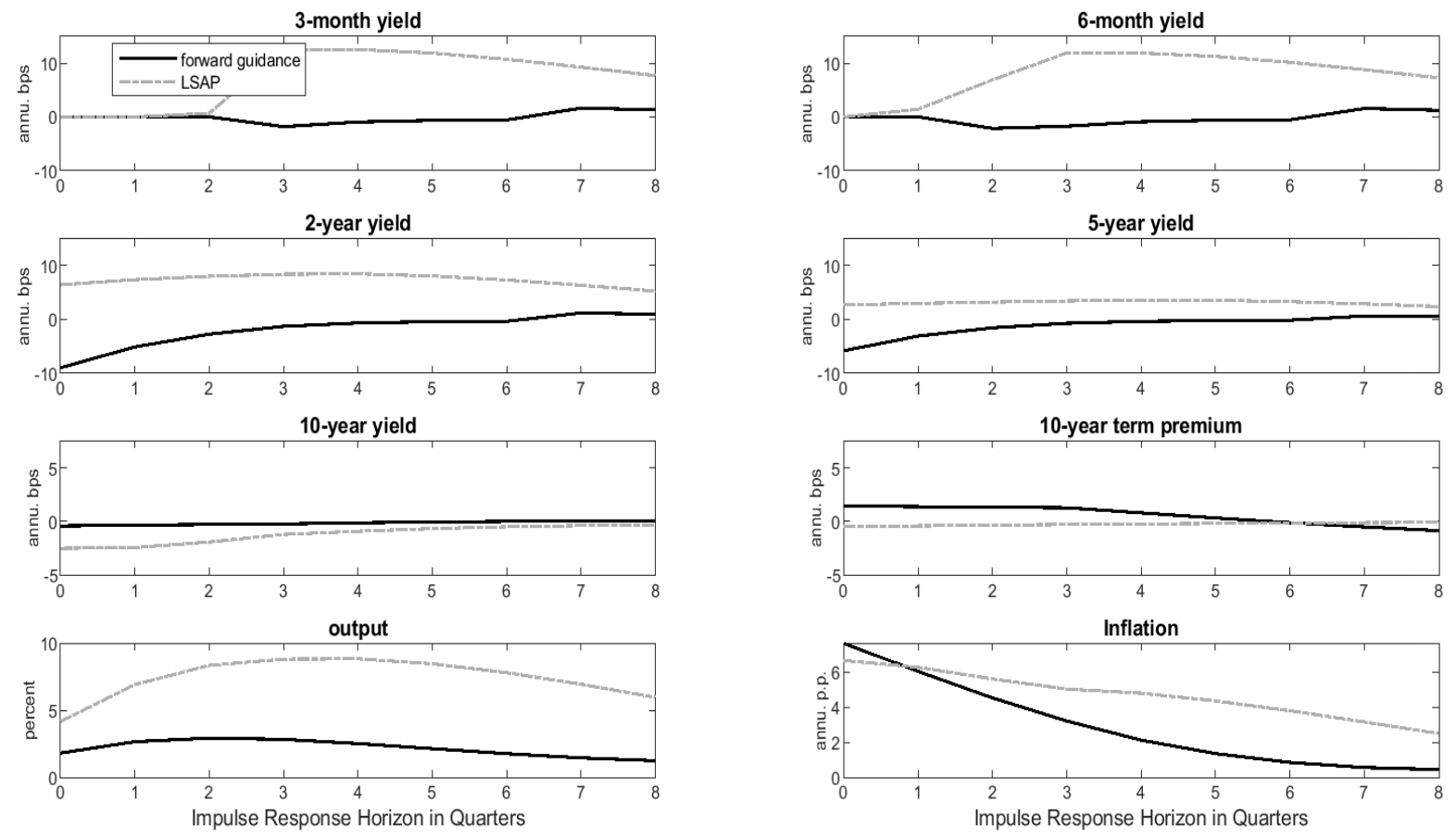

Notes: The figure shows the dynamic responses of the 3-month, 6-month, 2-year, 5-year and 10-year yields; 10 -year term premium; output; and inflation to the forward guidance surprise and LSAP surprise on November 25, 2008. 
Figure 10: Impulse Response on March 18, 2009
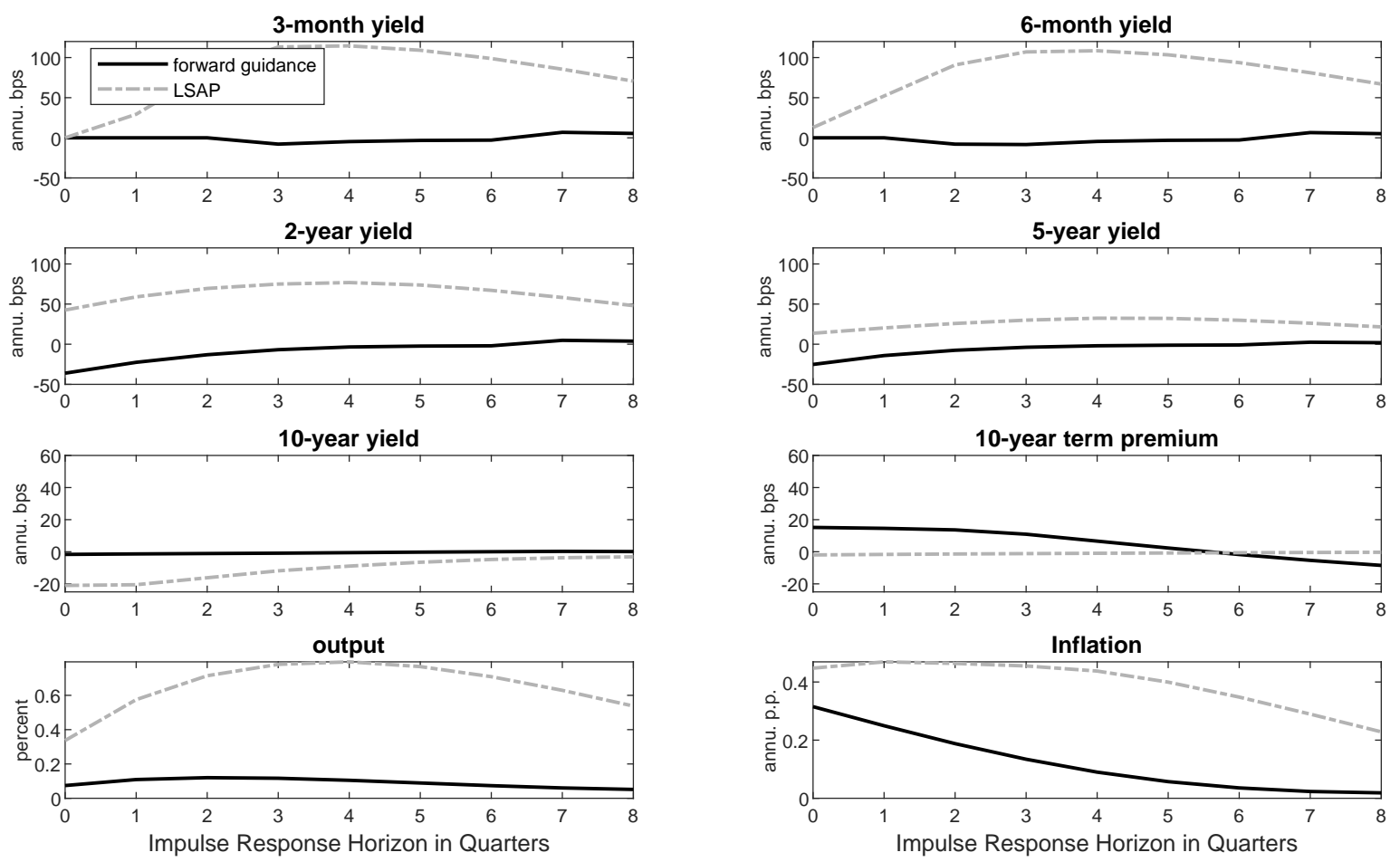

Notes: The figure shows the dynamic responses of the 3-month, 6-month, 2-year, 5-year and 10-year yields; 10 -year term premium; output; and inflation to the forward guidance surprise and LSAP surprise on March 18, 2009. 


\section{A Structural Model First-Order Conditions}

The first-order conditions of the household's decision problem are:

$$
\begin{aligned}
\frac{\partial u_{t}}{\partial c_{t}} W_{t} & =\chi l_{t}^{\phi} \\
\mathrm{E}_{t} \Lambda_{t, t+1} R_{t} & =1 \\
S_{h t}-S_{h} & =\frac{1}{\kappa_{s}} \mathrm{E}_{t} \Lambda_{t, t+1}\left(R_{k t+1}-R_{t}\right) \\
B_{h t}-B_{h} & =\frac{1}{\kappa_{b}} \mathrm{E}_{t} \Lambda_{t, t+1}\left(R_{b t+1}-R_{t}\right)
\end{aligned}
$$

where the household's stochastic discount factor is $\Lambda_{t, t+1} \equiv \beta \frac{\partial u_{t} / \partial c_{t}}{\partial u_{t} / \partial c_{t+1}}$.

Let $\Gamma_{t}$ be the Lagrange multiplier associated with the bankers' incentive constraint. The first-order conditions of the bankers' decision problem are:

$$
\begin{aligned}
& \mathrm{E}_{t} \widetilde{\Lambda}_{t, t+1}\left(R_{k t+1}-R_{t}\right)=\frac{\Gamma_{t}}{1+\Gamma_{t}} \lambda \\
& \mathrm{E}_{t} \widetilde{\Lambda}_{t, t+1}\left(R_{b t+1}-R_{t}\right)=\triangle \frac{\Gamma_{t}}{1+\Gamma_{t}} \lambda
\end{aligned}
$$

with

$$
\begin{aligned}
\widetilde{\Lambda}_{t, t+1} & \equiv \Lambda_{t, t+1} \Omega_{t+1} \\
\Omega_{t} & =1-\theta+\theta \frac{\partial V_{t}}{\partial n_{t}} \\
\frac{\partial V_{t}}{\partial n_{t}} & =\widetilde{\Lambda}_{t-1, t}\left[\left(R_{k t}-R_{t-1}\right) \phi_{t}+R_{t-1}\right]
\end{aligned}
$$

The constraints are:

$$
\begin{array}{rlll}
Q_{t} s_{p t}+\triangle q_{t}^{n} b_{t} & =\phi_{t} n_{t} & \text { if } & \Gamma_{t}>0 \\
<\phi_{t} n_{t} & \text { if } & \Gamma_{t}=0
\end{array}
$$

where

$$
\phi_{t}=\frac{\mathrm{E}_{t} \widetilde{\Lambda}_{t, t+1} R_{t}}{\lambda-\mathrm{E}_{t} \widetilde{\Lambda}_{t, t+1}\left(R_{k t+1}-R_{t}\right)}
$$

\section{B Model-Implied Yield Curve}

In this section, I show the details of the flexible yield curve interpolation method used in Section 2.6. 


\section{B.1 Yield Curve Interpolation When Away from the ZLB}

First I consider the case when the economy is far away from the ZLB, so that $i_{t}^{*}=i_{t}$ (the shadow rate equals the observed one-period rate). Suppose there are two possibly unobserved factors, $\left(\xi_{1 t}, \xi_{2 t}\right)$, which summarize everything that matters for determining interest rates. Their Q-measure dynamics are characterized by

$$
\begin{aligned}
& \xi_{1 t}=\phi_{1} \xi_{1 t-1}+\varepsilon_{1 t} \\
& \xi_{2 t}=\phi_{2} \xi_{2 t-1}+\varepsilon_{2 t}
\end{aligned}
$$

The one-period nominal interest rate $i_{t}$ is given by

$$
i_{t}=\xi_{1 t}+\xi_{2 t}
$$

Then the nominal forward rate at date $t$ at horizon $n$ is

$$
f_{n t}=E_{t}^{Q}\left(i_{t+n}\right)=\phi_{1}^{n} \xi_{1 t}+\phi_{2}^{n} \xi_{2 t}
$$

The yield at date $t$ with maturity $n$ is

$$
i_{n t}=n^{-1} \sum_{j=0}^{n-1} f_{j t}
$$

When $\phi_{1}=1$ and $\left|\phi_{2}\right|<1$, this framework implies the dynamic Nelson-Siegel model:

$$
i_{n t}=\xi_{1 t}+n^{-1} \frac{1-\phi_{2}^{n}}{1-\phi_{2}} \xi_{2 t}
$$

Equations (B.1) and (B.3) allow us to recover the two factors directly off the level of the one-period rate $i_{t}$ and the long-term rate $i_{N t}$ :

$$
\begin{aligned}
& \xi_{2 t}=\left(N^{-1} \frac{1-\phi_{2}^{N}}{1-\phi_{2}}-1\right)^{-1}\left(i_{N t}-i_{t}\right) \\
& \xi_{1 t}=i_{t}-\xi_{2 t}
\end{aligned}
$$

Once $\xi_{1 t}$ and $\xi_{2 t}$ are known, the entire yield curve can be interpolated using equation (B.3). 


\section{B.2 Yield Curve Interpolation at the Lower Bound}

Next I consider the case $i_{t}^{*}=\xi_{1 t}+\xi_{2 t}<\underline{\iota}, i_{t}=\underline{\iota}$. Wu \& Xia (2016) demonstrate that in equilibrium, the forward rates $f_{n t}$ can be approximated as

$$
\begin{aligned}
& f_{n t}^{*}=\xi_{1 t}+\phi_{2}^{n} \xi_{2 t} \\
& f_{n t}=\underline{\iota}+\sigma_{n} g\left(\frac{f_{n t}^{*}-\underline{\iota}}{\sigma_{n}}\right)
\end{aligned}
$$

where $g(z)=z \Phi(z)+\phi(z)$, with $\Phi(z)$ as the cumulative distribution function for a standard Normal variable, $\phi(z)$ as the density, and $\sigma_{n}$ as a parameter.

The relationship in equation (B.2) still holds, which allows us to infer $\left(\xi_{1 t}, \xi_{2 t}\right)$ from the model-implied interest rates $\left(i_{t}^{*}, i_{N t}\right)$ and thus interpolate the yield curve.

\section{B.3 Calibration for the Yield Curve Interpolation}

The values of $\underline{\iota}, \phi_{2}$ and $\sigma_{n}$ need to be calibrated. First $\underline{\iota}$ is chosen to be 0.25 basis points as the lower bound of overnight rate. Second, $\phi_{2}$ is chosen to match the average yield curve shape in the pre-ZLB period. In particular, I use 6-month, 1-, 2-, 5-, 7-, and 10-year monthly zero-coupon Treasury yield data from January 1990 to November 2007, a span that excludes the Great Inflation as well as the Great Recession periods. ${ }^{17}$ Over this sample, the average nominal 1-year Treasury yields is about 4.57 percentage points, and the average nominal 10-year Treasury yields is about 6 percentage points. $\phi_{2}$ is estimated to be 0.979 .

The function form of $\sigma_{n}$ follows Krippner (2016):

$$
\sigma_{n}=\sqrt{\rho_{1}^{2} n+\rho_{2}^{2} G\left(2 \phi_{3}, n\right)+2 \rho_{12} \rho_{1} \rho_{2} G\left(\phi_{3}, n\right)}
$$

where $\rho_{1}, \rho_{2}, \rho_{12}$ and $\phi_{3}$ are parameters; and $G\left(\phi_{3}, n\right)=\frac{1}{\phi_{3}}\left[1-\exp \left(-\phi_{3} n\right)\right] . \rho_{1}, \rho_{2}, \rho_{12}$ and $\phi_{3}$ are estimated from an arbitrage-free Nelson \& Siegel (1987) model with two statevariables (level and slope) using 6-month, 1-, 2-, 5-, 7-, and 10-year monthly zero-coupon Treasury yield data from January 2009 to November 2015. The values of $\rho_{1}, \rho_{2}, \rho_{12}$ and $\phi_{3}$ are assigned as $0.011,0.014,-0.739$ and 0.250 , respectively.

With these calibrated parameters, the model is able to reproduce these features of the data quite well: the average level of nominal yields in the model are between about 5.4 and 6.4 percentage points, with an upward slope of 109 bps. The 10-year and 2-year real rate spread is 69 basis points, equal to the average spread of TIPS during the 2004-07 period.

\footnotetext{
${ }^{17}$ The zero-coupon Treasury yield data is from Gürkaynak et al. (2007)'s online dataset.
} 
Figure B.1: Difference between Fitted Yield Curves from a No-Policy-Response Crisis When the Initial Condition Varies, FG Horizon Varies, the FG Persistence Varies, and the Definition of Unit Varies (from upper left to lower right)
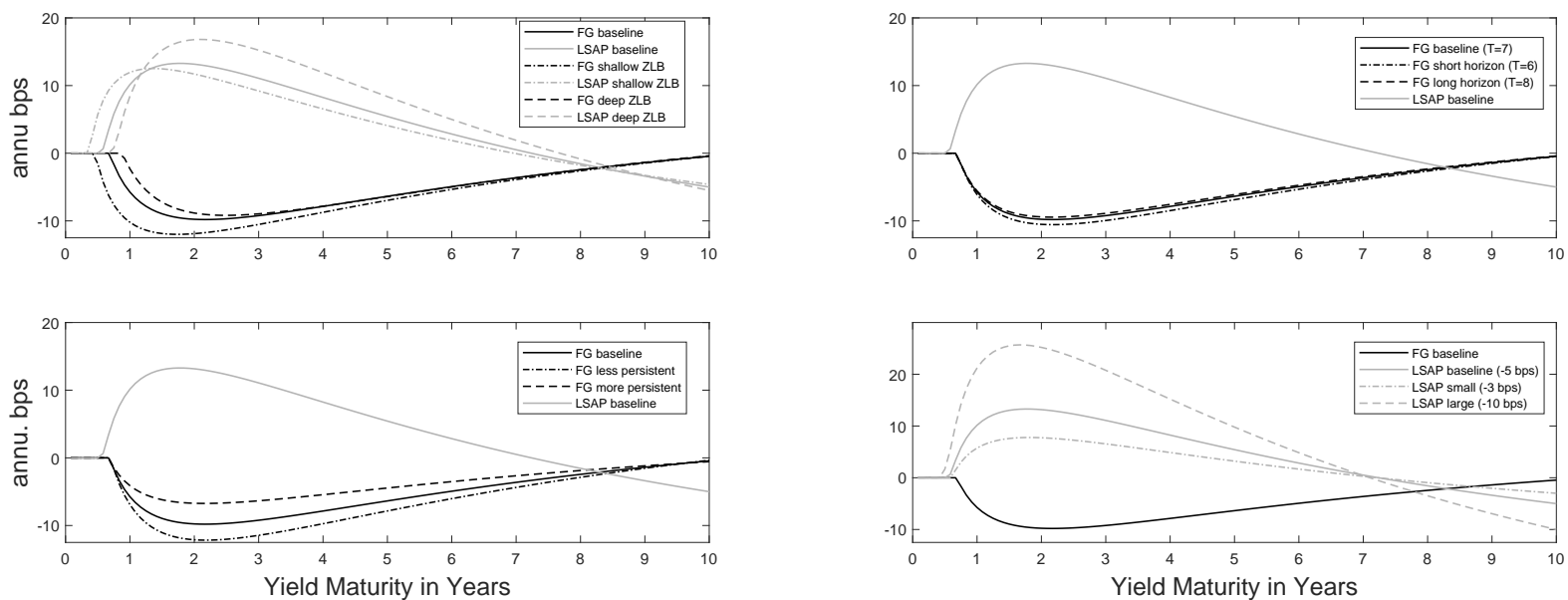
Figure B.2: Comparison of Monetary Policy Shocks Computed by Different Datasets
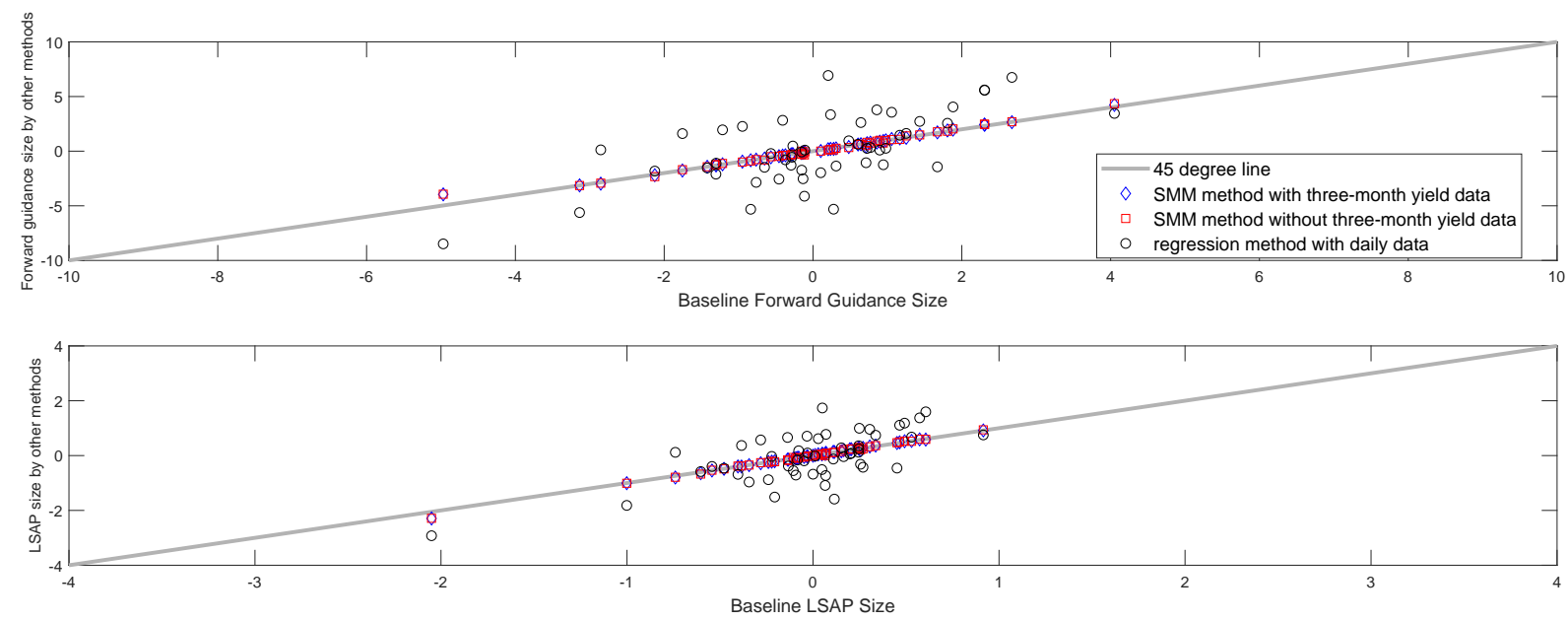
Figure B.3: Estimated Forward Guidance and LSAP Shocks Over Time, Including the Information Component

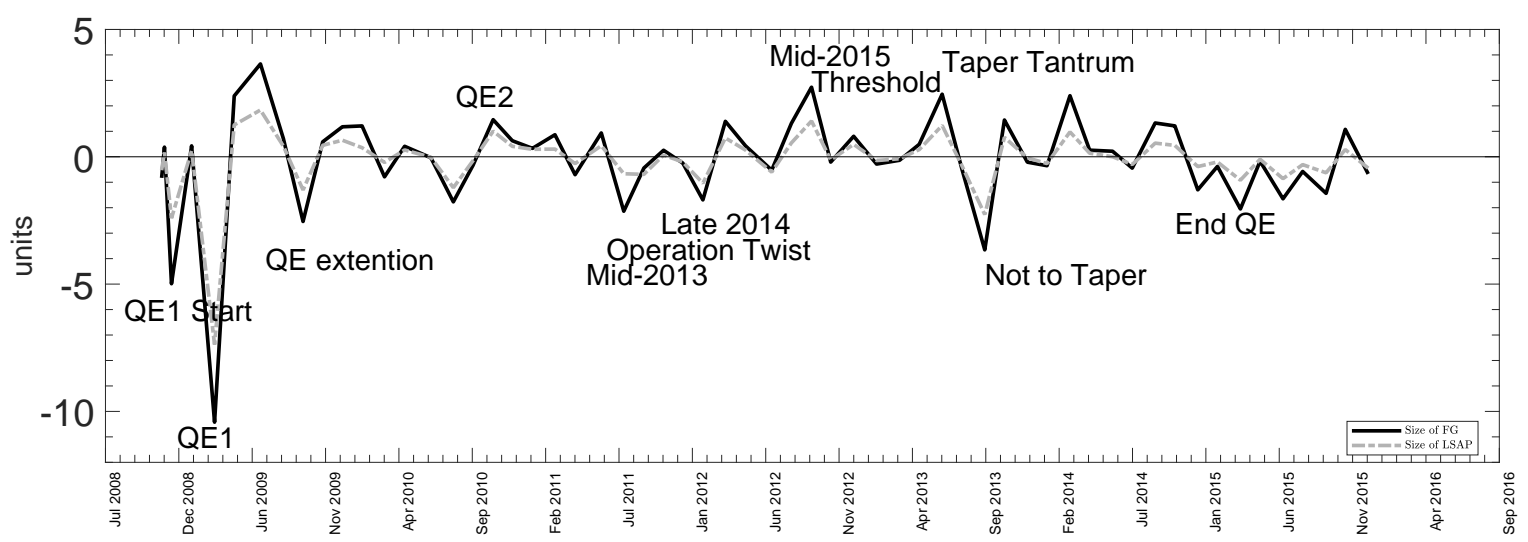


Table B.1: List of Event Dates and Relevant Monetary Policy Language

\begin{tabular}{|c|c|c|}
\hline Date & Forward Guidance & LSAP \\
\hline $25-$ Nov-08 & & $\begin{array}{l}\text { The initial announcement that the Federal } \\
\text { Reserve would purchase up to } \$ 100 \text { billion of } \\
\text { agency debt and up to } \$ 500 \text { billion of agency } \\
\text { MBS. }\end{array}$ \\
\hline 1-Dec-08 & & $\begin{array}{l}\text { Chairman Bernanke's speech on the Federal } \\
\text { Reserve Policies in the Financial Crisis, which } \\
\text { suggested that the Federal Reserve could pur- } \\
\text { chase longer-term Treasury securities in sub- } \\
\text { stantial quantities in order to stimulate the } \\
\text { economy. }\end{array}$ \\
\hline 16-Dec-08 & $\begin{array}{l}\text {...anticipates that weak economic } \\
\text { conditions are likely to warrant ex- } \\
\text { ceptionally low levels of the federal } \\
\text { funds rate for some time. }\end{array}$ & $\begin{array}{l}\text { The Federal Reserve will continue to consider } \\
\text { ways of using its balance sheet to further sup- } \\
\text { port credit markets and economic activity. }\end{array}$ \\
\hline \multicolumn{3}{|l|}{ 28-Jan-09 } \\
\hline 18-Mar-09 & ..for an extended period. & $\begin{array}{l}\text { The FOMC statement announced purchases } \\
\text { of Treasury securities of up to } \$ 300 \text { billion } \\
\text { and increased the size of purchases of agency } \\
\text { MBS and agency debt to up to } \$ 1.2 \text { trillion } \\
\text { and } \$ 200 \text { billion, respectively. }\end{array}$ \\
\hline \multicolumn{3}{|l|}{ 29-Apr-09 } \\
\hline \multicolumn{3}{|l|}{ 24-Jun-09 } \\
\hline 12-Aug-09 & & $\begin{array}{l}\text { FOMC statement dropped the "up to" in the } \\
\text { language to quantify the amount of longer- } \\
\text { term Treasury securities to be purchased. }\end{array}$ \\
\hline 23-Sep-09 & & $\begin{array}{l}\text { FOMC statement dropped the "up to" in the } \\
\text { language to quantify the amount of agency } \\
\text { MBS to be purchased. It also said that } \\
\text { agency debt and MBS purchases would be } \\
\text { slowed and finished by the end of } 2010 \mathrm{Q} 1 \text {, } \\
\text { rather than the end of } 2009 \text {. }\end{array}$ \\
\hline 4-Nov-09 & $\begin{array}{l}\text { The Committee ... continues to an- } \\
\text { ticipate that economic conditions, } \\
\text { including low rates of resource uti- } \\
\text { lization, subdued inflation trends, } \\
\text { and stable inflation expectations, } \\
\text { are likely to warrant exceptionally } \\
\text { low levels of the federal funds rate } \\
\text { for an extended period. }\end{array}$ & $\begin{array}{l}\text { FOMC statement stated that the exact } \\
\text { amount of agency debt to be purchased would } \\
\text { be about } \$ 175 \text { billion of agency debt, which is } \\
\text { less than the previously announced maximum } \\
\text { of } \$ 200 \text { billion. }\end{array}$ \\
\hline \multicolumn{3}{|l|}{ 16-Dec-09 } \\
\hline \multicolumn{3}{|l|}{ 27-Jan-10 } \\
\hline 16-Mar-10 & & \\
\hline
\end{tabular}




\begin{tabular}{|c|c|c|}
\hline Date & Forward Guidance & LSAP \\
\hline \multicolumn{3}{|l|}{$28-A p r-10$} \\
\hline \multicolumn{3}{|l|}{ 23-Jun-10 } \\
\hline 10-Aug-10 & & $\begin{array}{l}\text { To help support economic recovery in the con- } \\
\text { text of price stability, the Committee will } \\
\text { keep the Federal Reserve's holdings of se- } \\
\text { curities at their current level by reinvest- } \\
\text { ing principal payments from agency debt and } \\
\text { agency mortgage-backed securities in longer- } \\
\text { term Treasury securities. The Committee will } \\
\text { continue to roll over the Federal Reserve's } \\
\text { holdings of Treasury securities as they ma- } \\
\text { ture. }\end{array}$ \\
\hline 21-Sep-10 & & $\begin{array}{l}\text { The FOMC is prepared to provide additional } \\
\text { accommodation if needed. }\end{array}$ \\
\hline $3-N o v-10$ & & $\begin{array}{l}\text { The FOMC intends to purchase a further } \\
\$ 600 \text { billion of longer term Treasury securi- } \\
\text { ties by the end of the second quarter of } 2011 \text {, } \\
\text { a pace of about } \$ 75 \text { billion per month. }\end{array}$ \\
\hline \multicolumn{3}{|r|}{$P$ P } \\
\hline \multicolumn{3}{|l|}{ 26-Jan-11 } \\
\hline \multicolumn{3}{|l|}{ 15-Mar-11 } \\
\hline \multicolumn{3}{|l|}{$27-A p r-11$} \\
\hline 22-Jun-11 & $\begin{array}{l}\text { Modified the description of condi- } \\
\text { tions likely to warrant low rates to } \\
\text { include low rates of resource uti- } \\
\text { lization and a subdued outlook for } \\
\text { inflation over the medium run. }\end{array}$ & \\
\hline 9-Aug-11 & $\begin{array}{l}\text { The Committee currently antici- } \\
\text { pates that economic conditions ... } \\
\text { are likely to warrant exceptionally } \\
\text { low levels of the federal funds rate } \\
\text { at least through mid- } 2013 \text {. }\end{array}$ & \\
\hline 21-Sep-11 & & $\begin{array}{l}\text { The FOMC intends to purchase, by the end of } \\
\text { June 2012, } \$ 400 \text { billion of Treasury securities } \\
\text { with remaining maturities of } 6 \text { years to } 30 \\
\text { years and to sell an equal amount of Treasury } \\
\text { securities with remaining maturities of } 3 \text { years } \\
\text { or less. }\end{array}$ \\
\hline \multicolumn{3}{|l|}{ 21-Sept-11 } \\
\hline \multicolumn{3}{|l|}{$2-N o v-11$} \\
\hline \multicolumn{3}{|l|}{ 13-Dec-11 } \\
\hline \multicolumn{3}{|c|}{... at least through late 2014 . } \\
\hline \multicolumn{3}{|l|}{ 13-Mar-12 } \\
\hline 25-Apr-12 & & \\
\hline
\end{tabular}




\begin{tabular}{|c|c|c|}
\hline Date & Forward Guidance & LSAP \\
\hline 20-Jun-12 & & $\begin{array}{l}\text { The FOMC decided to continue through the } \\
\text { end of the year its program to extend the av- } \\
\text { erage maturity of its holdings of securities. } \\
\text { An accompanying statement by the Federal } \\
\text { Reserve Bank of New York clarifies that this } \\
\text { continuation will result in the purchase, as } \\
\text { well as the sale and redemption, of about } \$ 267 \\
\text { billion in Treasury securities by the end of } \\
2012 \text {. }\end{array}$ \\
\hline \multicolumn{3}{|l|}{ 1-Aug-12 } \\
\hline 13-Sep-12 & $\begin{array}{l}\text {...decided today to keep the target } \\
\text { range for the federal funds rate at } 0 \\
\text { to } 1 / 4 \text { percent and currently antic- } \\
\text { ipates that exceptionally low levels } \\
\text { for the federal funds rate are likely } \\
\text { to be warranted at least through } \\
\text { mid- } 2015 \text {. }\end{array}$ & $\begin{array}{l}\text { The FOMC agreed today to increase pol- } \\
\text { icy accommodation by purchasing additional } \\
\text { agency mortgage-backed securities at a pace } \\
\text { of } \$ 40 \text { billion per month. The Committee also } \\
\text { will continue through the end of the year its } \\
\text { program to extend the average maturity of its } \\
\text { holdings of securities as announced in June, } \\
\text { and it is maintaining its existing policy of } \\
\text { reinvesting principal payments from its hold- } \\
\text { ings of agency debt and agency mortgage- } \\
\text { backed securities in agency mortgage-backed } \\
\text { securities. These actions, which together will } \\
\text { increase the Committee's holdings of longer- } \\
\text { term securities by about } \$ 85 \text { billion each } \\
\text { month through the end of the year, should } \\
\text { put downward pressure on longer-term inter- } \\
\text { est rates, support mortgage markets, and help } \\
\text { to make broader financial conditions more ac- } \\
\text { commodative. }\end{array}$ \\
\hline \multicolumn{3}{|l|}{ 24-Oct-12 } \\
\hline 12-Dec-12 & & $\begin{array}{l}\text { The FOMC will continue purchasing addi- } \\
\text { tional agency mortgage-backed securities at a } \\
\text { pace of } \$ 40 \text { billion per month. The Commit- } \\
\text { tee also will purchase longer-term Treasury } \\
\text { securities after its program to extend the av- } \\
\text { erage maturity of its holdings of Treasury se- } \\
\text { curities is completed at the end of the year, } \\
\text { initially at a pace of } \$ 45 \text { billion per month. }\end{array}$ \\
\hline \multicolumn{3}{|l|}{ 30-Jan-13 } \\
\hline \multicolumn{3}{|l|}{ 20-Mar-13 } \\
\hline 1-May-13 & & \\
\hline
\end{tabular}




\begin{tabular}{|c|c|c|}
\hline Date & Forward Guidance & LSAP \\
\hline 19-Jun-13 & $\begin{array}{l}\text {..14 of } 19 \text { FOMC participants in- } \\
\text { dicated that they expect the first } \\
\text { increase in the target for the fed- } \\
\text { eral funds rate to occur in } 2015, \\
\text { and one expected the interest in- } \\
\text { crease to incur in } 2016 .\end{array}$ & \\
\hline \multicolumn{3}{|l|}{ 31-Jul-13 } \\
\hline \multicolumn{3}{|l|}{ 18-Sep-13 } \\
\hline \multicolumn{3}{|l|}{ 30-Oct-13 } \\
\hline 18-Dec-13 & $\begin{array}{l}\text {...anticipates, based on its assess- } \\
\text { ment of these factors, that it likely } \\
\text { will be appropriate to maintain the } \\
\text { current target range for the fed- } \\
\text { eral funds rate well past the time } \\
\text { that the unemployment rate de- } \\
\text { clines below } 6-1 / 2 \text { percent, espe- } \\
\text { cially if projected inflation contin- } \\
\text { ues to run below the Committee's } \\
2 \text { percent longer-run goal. }\end{array}$ & $\begin{array}{l}\text { Beginning in January, the Committee will } \\
\text { add to its holdings of agency mortgage- } \\
\text { backed securities at a pace of } \$ 35 \text { billion per } \\
\text { month rather than } \$ 40 \text { billion per month, } \\
\text { and will add to its holdings of longer-term } \\
\text { Treasury securities at a pace of } \$ 40 \text { bil- } \\
\text { lion per month rather than } \$ 45 \text { billion per } \\
\text { month. The Committee is maintaining its } \\
\text { existing policy of reinvesting principal pay- } \\
\text { ments from its holdings of agency debt and } \\
\text { agency mortgage-backed securities in agency } \\
\text { mortgage-backed securities and of rolling over } \\
\text { maturing Treasury securities at auction. The } \\
\text { Committee's sizable and still-increasing hold- } \\
\text { ings of longer-term securities should main- } \\
\text { tain downward pressure on longer-term inter- } \\
\text { est rates, support mortgage markets, and help } \\
\text { to make broader financial conditions more ac- } \\
\text { commodative, which in turn should promote } \\
\text { a stronger economic recovery and help to en- } \\
\text { sure that inflation, over time, is at the rate } \\
\text { most consistent with the Committee's dual } \\
\text { mandate. }\end{array}$ \\
\hline 29-Jan-14 & & $\begin{array}{l}\text { Beginning in February, the Committee will } \\
\text { add to its holdings of agency mortgage- } \\
\text { backed securities at a pace of } \$ 30 \text { billion per } \\
\text { month rather than } \$ 35 \text { billion per month, and } \\
\text { will add to its holdings of longer-term Trea- } \\
\text { sury securities at a pace of } \$ 35 \text { billion per } \\
\text { month rather than } \$ 40 \text { billion per month. }\end{array}$ \\
\hline
\end{tabular}




\begin{tabular}{|c|c|c|}
\hline Date & Forward Guidance & LSAP \\
\hline 19-Mar-14 & $\begin{array}{l}\text { With the unemployment rate near- } \\
\text { ing } 6-1 / 2 \text { percent, the Committee } \\
\text { has updated its forward guidance. }\end{array}$ & $\begin{array}{l}\text { Beginning in April, the Committee will add } \\
\text { to its holdings of agency mortgage-backed se- } \\
\text { curities at a pace of } \$ 25 \text { billion per month } \\
\text { rather than } \$ 30 \text { billion per month, and will } \\
\text { add to its holdings of longer-term Treasury } \\
\text { securities at a pace of } \$ 30 \text { billion per month } \\
\text { rather than } \$ 35 \text { billion per month. }\end{array}$ \\
\hline 30-Apr-14 & & $\begin{array}{l}\text { Beginning in May, the Committee will add to } \\
\text { its holdings of agency mortgage-backed secu- } \\
\text { rities at a pace of } \$ 20 \text { billion per month rather } \\
\text { than } \$ 25 \text { billion per month, and will add to } \\
\text { its holdings of longer-term Treasury securities } \\
\text { at a pace of } \$ 25 \text { billion per month rather than } \\
\$ 30 \text { billion per month. }\end{array}$ \\
\hline 18-Jun-14 & & $\begin{array}{l}\text { Beginning in July, the Committee will add to } \\
\text { its holdings of agency mortgage-backed secu- } \\
\text { rities at a pace of } \$ 15 \text { billion per month rather } \\
\text { than } \$ 20 \text { billion per month, and will add to } \\
\text { its holdings of longer-term Treasury securities } \\
\text { at a pace of } \$ 20 \text { billion per month rather than } \\
\$ 25 \text { billion per month. }\end{array}$ \\
\hline 30-Jul-14 & & $\begin{array}{l}\text { Beginning in August, the Committee will add } \\
\text { to its holdings of agency mortgage-backed se- } \\
\text { curities at a pace of } \$ 10 \text { billion per month } \\
\text { rather than } \$ 15 \text { billion per month, and will } \\
\text { add to its holdings of longer-term Treasury } \\
\text { securities at a pace of } \$ 15 \text { billion per month } \\
\text { rather than } \$ 20 \text { billion per month. }\end{array}$ \\
\hline 17-Sep-14 & & $\begin{array}{l}\text { Beginning in October, the Committee will } \\
\text { add to its holdings of agency mortgage- } \\
\text { backed securities at a pace of } \$ 5 \text { billion per } \\
\text { month rather than } \$ 10 \text { billion per month, and } \\
\text { will add to its holdings of longer-term Trea- } \\
\text { sury securities at a pace of } \$ 10 \text { billion per } \\
\text { month rather than } \$ 15 \text { billion per month. }\end{array}$ \\
\hline 29-Oct-14 & $\begin{array}{l}\text { The Committee today reaffirmed } \\
\text { its view that the current } 0 \text { to } 1 / 4 \\
\text { percent target range for the federal } \\
\text { funds rate remains appropriate. }\end{array}$ & $\begin{array}{l}\text { Accordingly, the Committee decided to con- } \\
\text { clude its asset purchase program this month. }\end{array}$ \\
\hline 17-Dec-14 & $\begin{array}{l}\text { The Committee judges that it can } \\
\text { be patient in beginning to normal- } \\
\text { ize the stance of monetary policy. }\end{array}$ & \\
\hline & & \\
\hline
\end{tabular}




\begin{tabular}{|c|c|c|}
\hline Date & Forward Guidance & LSAP \\
\hline 18-Mar-15 & $\begin{array}{l}\text { The Committee judges that an in- } \\
\text { crease in the target range for the } \\
\text { federal funds rate remains unlikely } \\
\text { at the April FOMC meeting. The } \\
\text { Committee anticipates that it will } \\
\text { be appropriate to raise the target } \\
\text { range for the federal funds rate } \\
\text { when it has seen further improve- } \\
\text { ment in the labor market and is } \\
\text { reasonably confident that inflation } \\
\text { will move back to its } 2 \text { percent } \\
\text { objective over the medium term. } \\
\text { This change in the forward guid- } \\
\text { ance does not indicate that the } \\
\text { Committee has decided on the tim- } \\
\text { ing of the initial increase in the tar- } \\
\text { get range. }\end{array}$ & \\
\hline 29-Apr-15 & & \\
\hline 17-Jun-15 & & \\
\hline 29-Jul-15 & & \\
\hline 17-Sep-15 & & \\
\hline $28-O c t-15$ & & \\
\hline 16-Dec-15 & $\begin{array}{l}\text { Given the economic outlook, and } \\
\text { recognizing the time it takes for } \\
\text { policy actions to affect future eco- } \\
\text { nomic outcomes, the Committee } \\
\text { decided to raise the target range } \\
\text { for the federal funds rate to } 1 / 4 \text { to } \\
1 / 2 \text { percent. }\end{array}$ & \\
\hline
\end{tabular}

